\title{
Cuando el «punto de vista nativo» no es el punto de vista de los nativos: Felipe Guaman Poma de Ayala y la apropiación de tierras en el Perú colonial
}

Et si le " point de vue indien " n'était pas le point de vue des indiens? : Felipe Guaman Poma de Ayala et l'appropriation de la terre dans le Pérou colonial When the «native point of view» was not how the natives saw it: Felipe Guaman Poma de Ayala and land appropiation in colonial Peru

José Carlos de la Puente Luna

\section{(2) OpenEdition} Journals

Edición electrónica

URL: http://journals.openedition.org/bifea/3357

DOI: 10.4000/bifea.3357

ISSN: 2076-5827

Editor

Institut Français d'Études Andines

Edición impresa

Fecha de publicación: 1 abril 2008

Paginación: 123-149

ISSN: 0303-7495

Referencia electrónica

José Carlos de la Puente Luna, «Cuando el «punto de vista nativo» no es el punto de vista de los nativos: Felipe Guaman Poma de Ayala y la apropiación de tierras en el Perú colonial », Bulletin de I'Institut français d'études andines [En línea], 37 (1) | 2008, Publicado el 01 octubre 2008, consultado el 26 noviembre 2020. URL : http://journals.openedition.org/bifea/3357 ; DOI : https://doi.org/10.4000/ bifea.3357

\section{(c) $(1) \odot$}

Les contenus du Bulletin de l'Institut français d'études andines sont mis à disposition selon les termes de la licence Creative Commons Attribution - Pas d'Utilisation Commerciale - Pas de Modification 4.0 International. 


\title{
Cuando el «punto de vista nativo» no es el punto de vista de los nativos: Felipe Guaman Poma de Ayala y la apropiación de tierras en el Perú colonial*
}

\author{
José Carlos de la Puente Luna**
}

\begin{abstract}
Resumen
A fines del siglo XVI, Felipe Guaman Poma de Ayala participó en una serie de disputas legales reclamando sus derechos a unas tierras ubicadas en la cercanía de la ciudad de Huamanga. Según su propia versión, él y otros parientes, quienes actuaban además como sus litigantes aliados, habían heredado dichas tierras de sus nobles antepasados, señores de todo el valle de Chupas. Tras engorrosas inspecciones, peticiones y decretos, los oficiales reales rechazaron sus pretensiones. Derrotado y humillado por las acusaciones de ser pleitista impostor, indio del común y falso señor étnico de las tierras que reclamaba, Guaman Poma se habría decidido entonces a denunciar estos y otros abusos en contra de los nativos en su famosa Nueva corónica y buen gobierno. Así planteada, la interpretación vigente nos conduce a aceptar que las tierras en disputa pudieron efectivamente pertenecer a sus ancestros como patrimonio familiar exclusivo y, por tanto, que el cronista experimentó una típica desposesión colonial en la cual la alianza de la justicia local y sus rivales legales lo privó de sus tierras ancestrales en Chupas. Contrariamente a lo que se ha venido sosteniendo, este trabajo argumenta que, en su calidad de señores del pueblo y valle de Chupas, tanto los ancestros de Guaman Poma, como sus herederos, se beneficiaron de los típicos mecanismos de apropiación de tierras y pastos comunes a manos de señores étnicos en el Perú colonial.
\end{abstract}

Palabras clave: Felipe Guaman Poma de Ayala, indios ladinos, primera composición general de tierras, tenencia de la tierra, Huamanga

* Agradezco a las editoras y al IFEA la oportunidad de presentar una versión completa de este texto, pues la exposición presentada en Sevilla era más bien una versión muy reducida - y por tanto incompleta — del argumento central esgrimido en este trabajo. Susan Ramírez, Javier Flores-Espinoza, Âlvaro Sialer y Chantal Caillavet contribuyeron con valiosísimas observaciones a las versiones precedentes.

** Texas Christian University. E-mail: j.c.delapuente@tcu.edu 


\title{
Et si le « point de vue indien » n'était pas le point de vue des indiens ? : Felipe Guaman Poma de Ayala et l'appropriation de la terre dans le Pérou colonial
}

\begin{abstract}
Résumé
À la fin du XVIè siècle, Felipe Guaman Poma de Ayala, s'impliqua dans une série de litiges judiciaires pour réclamer ses droits sur des terres proches de la ville de Huamanga. Il prétendait ainsi que ses parents (ses alliés dans ces actions en justice), avaient hérité ces terres de ses ancêtres nobles, Seigneurs de la totalité de la vallée de Chupas. Après de multiples inspections, pétitions et décrets, les officiers du Roi déboutèrent ses prétensions. Vaincu et humilié par l'accusation portée contre lui de plaider le faux, d'être un Indien du Commun et d'usurper la qualité de seigneur ethnique sur les terres qu'il réclamait, Guaman Poma se serait alors décidé à dénoncer ce type d'abus et bien d'autres, que l'on perpétrait contre les autochtones, dans sa fameuse Nueva corónica y buen gobierno. Ainsi posée, l'interprétation en vigueur nous amène à considérer que les terres en litige avaient bien pu en effet appartenir à ses ancêtres en tant que patrimoine familial exclusif et que donc, le chroniqueur se serait senti victime $d^{\prime}$ une spoliation typiquement coloniale : une alliance entre la Justice locale et ses adversaires légaux I'aurait privé, lui et les siens, de leurs terres ancestrales de Chupas. À l'encontre de l'interprétation qui a prévalu jusqu'à présent, cet article s'emploie à démontrer que, en tant que Seigneurs du village et de la vallée de Chupas, ce sont les ancêtres de Guaman Poma et leurs héritiers qui ont tiré parti des mécanismes d'appropriation des terres et pâtures communales typiques du Pérou colonial.
\end{abstract}

Mots clés : Felipe Guaman Poma de Ayala, Indiens «ladinos», Première «Composición» générale des terres, système foncier, Huamanga

\section{When the «native point of view» was not how the natives saw it: Felipe Guaman Poma de Ayala and land appropiation in colonial Peru}

\begin{abstract}
In the closing years of the 16th century, Felipe Guaman Poma de Ayala pressed legal claims to a tract of lands near the city of Huamanga. According to his testimony, he and some relatives who were also his legal partners had inherited the lands from their noble ancestors, lords of the entire Valley of Chupas. After numerous inspections, petitions, and royal decrees, the local offcials dismissed Guaman Poma's claims. Having lost his «family» lands and humiliated by the accusation of being a humble Indian and a fake lord, Guaman Poma decided to denounce these and other abuses against the natives in his famous Nueva corónica y buen gobierno. Set forth in those terms, the current interpretation leads us to accept that the lands under litigation could in fact have belonged to his ancestors, and hence that the author and his family experienced a typical colonial dispossession in which the alliance of the local justice and the rival counterclaimants evicted the family from their ancestral lands in Chupas. I will argue instead that, as native lords of the town and Valley of Chupas, Guaman Poma's alleged ancestors and then their heirs participated in a typical process of appropriation of previously open common lands and pastures.
\end{abstract}

Key words: Felipe Guaman Poma de Ayala, ladinos indians, primera composición general de tierras, land tenure, Huamanga 


\section{INTRODUCCIÓN: LA TESIS DE LA DESPOSESIÓN}

A fines del siglo XVI, Felipe Guaman Poma de Ayala, autor de la célebre carta ilustrada al Rey, participó en una serie de disputas legales reclamando sus derechos a un conjunto de tierras ubicadas en el valle de Chupas, muy cerca de la ciudad de Huamanga. Según su testimonio, él y otros parientes, quienes actuaban como sus litigantes aliados, habían heredado dichas tierras de sus nobles antepasados, «señores y casiquez Principales» de todo el «Valle de Chupas», pero les estaban siendo usurpadas por varios personajes indígenas y españoles. Cuatro fueron los «títulos» esgrimidos por Guaman Poma ante las autoridades virreinales. Según el primero, el emperador Túpac Inca Yupanqui había «confirmado» las «tierras y haciendas» que sus ancestros habían adquirido para sí luego de expulsar a los antiguos habitantes de Chupas, un grupo de indios Angaraes. El Inca había señalado luego los linderos de estas tierras familiares con mojones — señales permanentes para fijar los linderos de chacras, términos y fronteras-. El segundo título era un misterioso decreto colonial que había «confirmado» dichas posesiones para los ancestros del cronista a cambio de sus servicios a la Corona durante la fundación de Huamanga (1539). Entre 1570 y 1575 , un tercer título había asegurado la posesión territorial previa. Finalmente, la primera composición general de tierras había vuelto a confirmar los títulos familiares a las chacras de Chupas, alrededor de 15951.

Solo dos años después, en 1597, Guaman Poma inició las mentadas acciones judiciales para proteger las tierras heredadas de varios grupos e individuos a quienes el cronista calificó de «intrusos». Tras engorrosas inspecciones, peticiones y decretos, los oficiales reales finalmente rechazaron sus pretensiones, favoreciendo, entre otros, a los indios Chachapoyas que habían venido reclamando (y utilizando) algunas de las tierras para sí. En 1600, una severísima sentencia se pronunció contra Guaman Poma, ordenándole que marchara al destierro. Derrotado y humillado por las acusaciones de ser pleitista impostor, indio del común y falso señor étnico de las tierras que reclamaba, Guaman Poma se habría decidido entonces a denunciar estos y otros abusos en contra de los nativos en su famosa Nueva corónica y buen gobierno (Guillén, 1969: 92; Zorrilla, 1977; Adorno, 1993; 2000: xxiii y ss.; 2001: 31, 39).

Al menos, eso es lo que sostiene la interpretación prevaleciente. Sin duda, la derrota legal de Guaman Poma actuó como uno de los poderosos incentivos detrás del tono de denuncia de la Nueva corónica. Así planteada, sin embargo, la interpretación vigente nos conduce a aceptar que las tierras en disputa pudieron efectivamente pertenecer a sus ancestros y, por tanto, que el cronista experimentó una típica desposesión colonial. De acuerdo con esta interpretación, basada en la imagen que de sí mismo el cronista buscó proyectar, la alianza entre la justicia virreinal y los litigantes rivales despojó a la familia de sus tierras ancestrales. Nathan Wachtel (1973: 175), por ejemplo, escribió que Guaman Poma fue «desposeído de sus bienes por un curaca cómplice de los españoles». Raquel Chang-Rodríguez (1995: 100), por su parte, afirmó que Guama Poma inició su pleito contra los indios Chachapoyas «con el propósito de recuperar tierras en Guamanga» [énfasis mío]. En palabras recientes de Rolena Adorno:

1 Para los títulos, véase Prado \& Prado, 1991: f. 64v y Guaman Poma, 1992: 918-22. Por cuestiones de espacio, en algunos casos escribiré «Guaman Poma» para referirme al bando de litigantes aliados del cronista. Asumo que Guaman Poma decía la verdad al presentar a estos litigantes como sus parientes y descendientes de los mismos señores étnicos. Para algunas de las inconsistencias en las referencias que hace el cronista a su familia y ancestros, véase Porras, 1948; Varallanos, 1979; Macera, 1991; Husson, 1995. Para otros documentos vinculados a este litigio, véase Guillén, 1969; Zorrilla, 1977; Varallanos, 1979: 210-212; Pereyra, 1997. 
«Luego de esa fecha [1600], cuando el sistema de justicia colonial español en el cual él había confiado lo traicionara, Guaman Poma emprendió su propio proyecto literario independiente» (Adorno \& Boserup, 2005: 220)².

Esta interpretación se basa en un conjunto de supuestos que este artículo somete a revisión.

En efecto, en el marco más amplio de estudios sobre el cronista, la Nueva corónica ha sido ponderada por su «valor etnográfico», es decir, su utilidad para el conocimiento de las sociedades andinas prehispánicas. Diversos autores se han ocupado de la inclusión de frases en los idiomas nativos, la aportación de materiales gráficos sobre las poblaciones indígenas, la famosa descripción de las categorías de edad y el rechazo del autor — consciente o inconsciente - al marcado Cuzco-centrismo de otros testimonios (Rowe, 1958; Murra, 1987; 1992a; Wachtel, 1977; Adorno, 1978). Más específicamente, varios autores han resaltado lo que ellos perciben como la visión auténticamente «andina» de Guaman Poma. En esta línea, Wachtel (1973: 167) presenta a Guaman Poma como un «indio puro» que percibía el mundo colonial «a través de categorías auténticamente indígenas», un individuo cuyos «esquemas mentales» y «sistemas de pensamiento» eran diferentes del «nuestro». Por su parte, Juan Ossio (1973: 156) caracteriza la visión del cronista sobre el pasado y la historia - pero también sobre el espacio- como perteneciente a «un pensamiento que se enmarcaba en categorías ajenas al mundo europeo que le era contemporáneo». Los trabajos dedicados al famoso «Mapamundi del reino de las Indias» inciden en este mismo aspecto: el mapa no sería otra cosa que una «representación puramente indígena del universo» (Wachtel, 1973: 177). En esta representación ideal del «Tahuantinsuyo» (un Imperio con cuatro «provincias» y un centro), el orden espacial sería concebido por Guaman Poma a partir de «categorías andinas» tradicionales (dualidad, cuadripartición) y de la clásica oposición «Hanan»/«Hurin»3. Finalmente, en su discusión acerca de la «visión indígena» de Guaman Poma sobre el uso y la tenencia de la tierra, John Murra (1992a: xiv) sugiere que el cronista «era consciente de la incomprensión reinante entre los europeos sobre el uso y acceso a las tierras» en los Andes, por lo que en su Nueva corónica se habría tomado el trabajo de intentar explicarles «el acceso universal» de los andinos a este «bien fundamental». Según la interpretación de Murra (1992a: xiv), Guaman Poma trató de demostrar en su obra que:

«Este acceso [a la tierra] no se podía comprar; no se heredaba de algún familiar muerto, ni había que merecerlo. Se obtenía al nacer en una unidad étnica y de parentesco».

Ahora bien, ¿̇hasta qué punto, en el caso específico del uso y la tenencia de la tierra, el punto de vista personal de Guaman Poma no representa el punto de vista «indígena tradicional», «la visión andina nativa» — como se le ha denominado en repetidas ocasiones-, sino una posición mucho más cercana a la visión española oficial de la tierra de lo que hemos querido aceptar hasta ahora? Más aun, ¿̇es posible sugerir que, en el caso del litigio por las tierras «familiares» de Chupas, las pretensiones y los argumentos del cronista contradijeron las repetidas afirmaciones contenidas en la Nueva corónica acerca de que la tierra en el mundo andino era sapsi, bien común de todos?4. Las páginas que siguen proponen una interpretación alternativa sobre este acontecimiento central en la vida del cronista a partir

2 Todas las traducciones son mías.

3 Véase, entre otros, Adorno, 1979; 1982; 1987; 1991; 1992; 2000; López-Baralt, 1979; 1992; Ossio, 1970; 1973; Wachtel, $1973 ; 1977$. Reproduzco la forma «Hurin» porque es así como aparece en estos trabajos. Sobre el uso más apropiado del manido término — «Lurin» o «Rurin» dependiendo del dialecto—, véase Cerrón-Palomino, 1992.

4 Sobre la noción andina de sapsi, que González Holguín glosa como «cosa común de todos», remitimos al citado trabajo de Murra (1992a: xv), el mismo que recoge los pasajes pertinentes de la Nueva corónica. En tiempos coloniales, los recursos de sapsi incluían tierras, ganado, comida, tejidos y, posteriormente, el dinero que se guardaba en las llamadas «cajas de comunidad» y que se usaba para los más diversos fines. 
del análisis de los efectos dramáticos de la aculturación en la percepción indígena colonial de la tierra y, sobre todo, en la representación del espacio y del territorio.

En efecto, la tesis establecida sobre la «desposesión»o «traición» colonial se sostiene en la falsa premisa de que los supuestos antepasados de Guaman Poma pudieron efectivamente haber poseído los terrenos de Chupas como patrimonio familiar exclusivo. Esta opción era, sin embargo, culturalmente imposible antes de la conquista española. Ni los rivales legales del cronista ni las autoridades coloniales (o la alianza de ambos, para tal caso) pudieron haber desposeído a la parentela de Guaman Poma de «algo» de lo que sus antepasados cercanos o lejanos no pudieron haber sido dueños ni propietarios: la tierra. Para algunos autores, los emperadores Incas, los señores étnicos locales o, inclusive, algunos individuos particulares podían gozar del uso exclusivo de terrenos en una especie de propiedad familiar privada (Morote, 1975: 22, 63; Espinoza Soriano, 1978: 232-233; Wachtel, 1982: 214-215, 219; Macera, 1991: 28-32). Según esta visión, los parientes del cronista habrían sido «dueños» de Chupas desde antes de la Conquista, pues sería Chupas, en palabras de Pablo Macera, el «curacazgo-hacienda» de este célebre clan andino (Macera, 1991: 45). Sin embargo, conceptos occidentales sobre la tenencia de la tierra, incluido el de la propiedad individual y exclusiva, no se aplican a la región de Huamanga antes de la llegada de los españoles. Sin desmedro de aquello que los tribunales coloniales finalmente reconocieron como reclamos «válidos», los «títulos» de tierras prehispánicos y coloniales, a pesar de constituir una estrategia legal muy efectiva, no se referían al escenario prehispánico real (o incluso posible). Dada la importancia de la tierra en el Perú del siglo $\mathrm{XVI}$, la preocupación principal de estos títulos, modelados para satisfacer las exigencias propias del sistema legal para el cual se generaron, no era el pasado prehispánico, sino el acuciante presente colonial. Solo a partir de esta premisa podemos esclarecer los reclamos de tierras, supuestos títulos e intereses contrapuestos en los que Guaman Poma se vio envuelto a fines de la década de 1590.

Una interpretación alternativa de las batallas legales por las tierras de Chupas parte de la consideración de tres asuntos interrelacionados, los cuales estructuran las tres secciones en que se divide este ensayo. Primero, es preciso establecer el escenario colonial pertinente, contrastando los sistemas andino prehispánico y español de tenencia de la tierra en Huamanga. Rolena Adorno ha afirmado correctamente que:

«Los reclamos de Guaman Poma contra los intrusos [en Chupas] ilustran la transición desde el sistema andino de tenencia de la tierra hacia el concepto europeo de propiedad personal, así como la confusión acerca de la posesión legítima a cualesquier tierras en disputa» (Adorno, 1993: 65).

Siendo esto cierto, Adorno parece no haber tomado realmente en consideración los efectos dramáticos que la «transición» y la «confusión» (es decir, el choque de sistemas culturales) ocasionaron en los títulos y reclamos de tierras de la década de 1590, incluida su naturaleza híbrida como artefactos típicamente coloniales. El tremendo impacto de las ideas de propiedad privada y territorialidad continua entre las poblaciones nativas de Huamanga transformó drásticamente la noción misma de «tierra» y la concepción andina de territorio. Consciente o inconscientemente, los litigantes por las tierras de Chupas describieron un paisaje social que solo había podido cobrar forma en las décadas inmediatamente posteriores a la Conquista.

Segundo, es necesario concentrarse en los títulos «prehispánicos» esgrimidos por Guaman Poma con el fin de esclarecer en qué sentido los hitos o mojones prehispánicos, así como su contraparte colonial (ambos mencionados reiteradamente en los títulos), corresponden a dos sistemas culturales distintos. A pesar de los argumentos del cronista $-\mathrm{y}$ de muchos otros andinos en el siglo XVI— acerca de que el Inca «confirmó» las tierras conquistadas 
por sus ancestros y luego las señaló con mojones, los señores del Cuzco no premiaban a los señores leales con pedazos de tierra ni con terrenos claramente delimitados, tal como el Rey lo haría años después. Los «gobernadores provinciales» y «visitadores» incas no establecían «fronteras y jurisdicciones» territoriales para todo el «reino», como lo sugiere Adorno, pues esto responde más bien a una lógica española de territorialidad continua. En tal sentido, la afirmación que «para la década de 1590, a Guaman Poma sólo le quedaba imaginar aquellos días pasados en que estos funcionarios supuestamente incorruptibles establecían linderos y jurisdicciones en todo el reino»(Adorno, 1993: 60-61) puede despertarnos alguna nostálgica evocación —esto porque Guaman Poma pudo haberlo efectivamente imaginado - pero nos remite a una inexactitud histórica.

Tercero, es preciso analizar más en detalle los títulos coloniales de tierras presentados por Guaman Poma y sus litigantes aliados con el fin de evitar una lectura condicionada por los contenidos de la Nueva corónica y por la importancia capital de su autor. Las disputas por linderos del cronista, ocurridas más de cincuenta años después del primer contacto con los europeos, no «se prolongaban hacia atrás desde los tiempos coloniales hacia las tradiciones andinas autóctonas» (Adorno, 1993: 60-61). Si bien existían potenciales y reales situaciones de conflicto en ambas sociedades, estas disputas emergían de nuevas tradiciones, así como de concepciones divergentes acerca del uso de recursos como la tierra. Contrariamente a lo que se ha venido sosteniendo, argumentaré que, en su calidad de curacas del pueblo y valle de Chupas, tanto los ancestros de Guaman Poma (si es que en realidad lo fueron) como sus herederos se beneficiaron de los típicos mecanismos de apropiación de tierras y pastos comunes a disposición prioritariamente de los señores étnicos. A pesar de la artificiosa presentación legal de un curacazgo territorial de Chupas, los señoríos prehispánicos no eran unidades territoriales con fronteras geográficamente delimitadas y sus jefes étnicos no poseían la tierra (a lo más, la administraban). A esto es preciso agregar que aquellos curacas envueltos en la apropiación de tierras comunes podían beneficiarse notablemente de la alianza temporal con indígenas aculturados y buenos conocedores de los vericuetos legales pertinentes, tal como Felipe Guaman Poma.

Así, es preciso reconsiderar las verdaderas implicaciones de las batallas judiciales por los terrenos de Chupas para la identidad colonial del cronista indio. Su importancia abrumadora para los estudios andinos no debería inhibirnos de ofrecer una versión más crítica de esta historia. En el nuevo contexto de la Huamanga colonial, aquello culturalmente imposible en términos andinos no solo se volvió posible, sino también asible y hasta rentable. Todos los litigantes envueltos en la historia que sigue a continuación se embarcaron en la misma empresa colonial: la apropiación de tierras como propiedad privada y exclusiva.

\section{ANTIGUOS SEÑORES Y NUEVOS PUEBLOS: EL CAMBIANTE PAISAJE SOCIAL}

Una de las tareas primordiales de la etnohistoria andina ha sido el desentrañar los significados específicos que las poblaciones prehispánicas atribuían a conceptos culturalmente sensibles como «tributo», «provincia», «imperio» y «tierra». Dichos significados diferían, a veces de manera notable, de sus contrapartes europeas, a pesar de las aparentes similitudes que podrían desprenderse de una lectura literal de las fuentes. Aquellos andinos envueltos en litigios por tierras durante el temprano Periodo Colonial se mostraron ajenos a ciertos conceptos españoles básicos sobre la tenencia de la tierra, como la propiedad privada y exclusiva y los derechos inalienables, es decir, el control exclusivo por un individuo o grupo sobre un pedazo delimitado de tierra, independientemente de si estuviera en uso o no, hasta que los derechos sobre éste se transfirieran a un nuevo propietario. A pesar de que distintos 
linajes prehispánicos podían compartir el uso de campos y pastos naturales, estos recursos no les pertenecían en propiedad exclusiva. Eran más bien parte del dominio precario y temporal (sujeto al uso) del grupo. Sus miembros no eran dueños de la tierra per se, pues ésta actuaba más como un médium que como un ítem. La tierra era usada y compartida sobre la base de varios mecanismos rituales. Las aguas, bosques y pastos naturales estaban, al menos en teoría, abiertos al uso de cualesquier grupos étnicos. De forma similar, la tierra deshabitada y sin trabajar, así como los recursos sobre y debajo de ella, estaban disponibles para cualquier grupo que los cultivara y los protegiera, introduciendo en ellos las mejoras necesarias para la agricultura o la ganadería.

En sentido más estricto, solo el uso continuo y las mejoras infraestructurales daban al grupo ciertos derechos y cierta jurisdicción — de forma aproximada a como los entendemos hoy - al producto del trabajo organizado: cosechas, lana, árboles frutales y canales, por ejemplo. A pesar de que estas reivindicaciones podían efectivamente establecer ciertos derechos al uso continuo o de largo plazo de los terrenos, si el grupo étnico abandonaba el cultivo de dichos campos, cualquier otro grupo podía volver a cultivarlos y reclamar derechos sobre lo que ahora se producía en ellos. Esta distinción entre la ocupación y jurisdicción temporal de la tierra, por un lado, y el título absoluto y exclusivo a la misma, por otro, resulta crucial para entender los reclamos legales de Guaman Poma a las tierras del valle de Chupas5.

Además de la ausencia de propiedad exclusiva de la tierra, las poblaciones andinas de Huamanga compartían un muy conocido modelo de ocupación territorial discontinua (recursos dispersos, ubicados en zonas ecológicas complementarias). Las relaciones de parentesco eran la premisa detrás de la organización de la producción y la participación en el proceso de distribución. Junto con el parentesco, el culto a los ancestros comunes y otros marcadores étnicos eran más importantes al momento de definir las identidades andinas prehispánicas que una eventual ocupación continua de un territorio, cosa que, en todo caso, la geografía solo rara vez permitía. Los colonos dispersos seguían considerándose sujetos a sus señores distantes, preservando su afiliación étnica y sus obligaciones sociales para con el grupo de origen. Las fuentes históricas sobre los Andes prehispánicos, antes que señoríos territoriales o provincias, presentan más bien un escenario altamente fragmentado en términos étnicos. También en Huamanga, los desplazamientos de diversas poblaciones para acceder a recursos como la coca, el ají o la sal debieron ser un proceso muy fluido, sujeto a constante negociación. Caviñas, Acos, Angaraes, Huayacondos, Huaros, Pariscas, Chilques, Chancas, Papres, Totos, Tanquihuas, Quichuas, Cañaris, Quitos, Aymaraes, Lucanas, Soras, Chalcos, Huachos, Yauyos, Huancas, y Chocorvos -la lista no es exhaustiva- debieron estar en constante movimiento con el fin de maximizar su acceso a los recursos, especialmente en áreas de alta proliferación étnica como Chupas (Murra, 1975; Huertas, 1981: 137; 1998: 10-11; Pärssinen, 1992: 294).

A esto se agrega que la presencia del centro administrativo y religioso inca de Vilcashuamán, en la zona bajo la futura jurisdicción de Huamanga, estimuló la proliferación de diversas colonias multiétnicas en el área, con asentamientos de distintos grupos étnicos y trabajadores temporales o mitimaes entremezclados en el paisaje. De modo sintomático, en 1542, las autoridades del cabildo de Huamanga afirmaron, quizá con cierta exageración, que «todos los indios de esta provincia [son] mytimas» (Rivera Serna, 1966: f. 51r; también Zuidema,

5 Para la síntesis ofrecida en estos dos párrafos, véase Murra, 1980a: 29-30; 1980b: 275, 285; Rowe, 1982; Pease, 1986: 11; Rostworowski, 1988: ff. 92v, 95r, 106r; Noejovich, 1996; Ramírez, 1996: 16-17, 49; 2005: 40, $227-$ 228. Estos trabajos enfatizan la ausencia de propiedad privada de la tierra en los Andes prehispánicos, así como la existencia de derechos sobre lo que se producía en la tierra antes que a la tierra misma. Por obvias razones, ésta no es, ni puede ser, una presentación exhaustiva del problema de la tenencia de la tierra en los Andes prehispánicos. 
1967: 70; Pärssinen, 1992: 294). Entre sus tareas, los mitimaes debían cortar madera, construir canales y preparar los terrenos agrícolas. Sin embargo, estos trabajadores no tenían derechos exclusivos sobre dichas tierras; terminada su labor, regresarían a sus lugares de origen, mientras que dichas tierras serían reutilizadas por otros grupos, fuera para sí o para beneficio del Estado inca (Rowe, 1982).

Para no caer en el error de imaginar una situación idílica, sin embargo, es preciso tener presente que la precaria coexistencia, la negociación continua y la abierta confrontación por recursos caracterizaron a estas colonias multiétnicas. Las disputas por el acceso a los recursos podían ser endémicas. En tal contexto, ninguno de los grupos locales o forasteros establecidos en la región alrededor de Huamanga podría haber reclamado la propiedad exclusiva de la tierra. El alto nivel de complejidad que una situación tal podía alcanzar trajo como resultado la proliferación de jurisdicciones sobre poblaciones dispersas y derechos superpuestos y compartidos a la tierra y a otros recursos «naturales» (las aguas, los bosques, los pastos). En muchos casos, solo un poder supremo y en gran medida externo como el de los incas podía dirimir las disputas entre colonos y señores étnicos rivales (Stern, 1993: 21, 31). Determinar ahora - o incluso en el tardío siglo XVI-qué parcelas específicas «pertenecieron» a cada uno de los grupos étnicos establecidos alrededor de Huamanga no sería solo una tarea muy difícil, sino quizás una empresa inútil, pues solo aportaría una visión distorsionada del contexto prehispánico de uso discontinuo (mas no de propiedad) de la tierra.

Cambios drásticos, especialmente la temprana introducción del concepto español de propiedad de la tierra, vinieron a trastornar este escenario tras la fundación de Huamanga (1539). Pronto, en la década de 1540, varios vecinos españoles pidieron al Cabildo la asignación de algunas tierras para los indios que habían recibido en encomienda. Así, los señores étnicos y sus encomenderos recibieron los primeros «títulos» a los campos y pastos que tenían en uso en dicho momento. Los grupos étnicos circundantes comenzaron a establecerse en el territorio continuo a ellos asignado, mientras que los antiguos mitimaes conservaron las tierras que habían estado cultivando temporalmente antes de la Conquista (Huertas, 1981; 1998). Éstas y otras poblaciones nativas se vieron forzadas a adaptarse rápidamente a las nuevas reglas sociales y legales impuestas sobre el paisaje huamanguino.

La política de las reducciones, implementada entre 1550 y 1580, trastocó aún más los patrones andinos de asentamiento y uso de la tierra. En 1557, los oficiales del Rey habían reubicado cientos de caseríos dispersos, antes organizados en 676 asentamientos, en solo 252 pueblos de traza española. En 1570, el virrey Toledo ordenó la implementación oficial y coordinada de las primeras reducciones o pueblos de indios en Huamanga. Los funcionarios encargados concentraron 17 «pueblos» ubicados alrededor de la ciudad -incluidos los de Chupas - en solo siete nuevos asentamientos. En ciertos casos, las autoridades dividieron a los miembros de un grupo étnico entre varios pueblos; en otros, agruparon a linajes de grupos distintos en una sola reducción, creando así nuevas entidades político-administrativas cuya influencia posterior en la historia de las poblaciones andinas coloniales sería decisiva (Bandera, 1965: 176; Zuidema, 1967: 74; Espinoza Soriano, 1978: 238-239; Huertas, 1981: 135; 1998: 17). Igual de importante, la implementación de las reducciones conllevó la asignación de las primeras tierras «del común» — comunitarias o comunales - entre sus miembros. Dichas tierras debían estar claramente identificadas y delimitadas, requisito que fomentó aún más la necesidad de privatizar tierras entre las nuevas corporaciones indígenas. A pesar de que las autoridades debían «confirmar» estas tierras comunales, tales «comunidades indígenas» no habían existido como tal anteriormente (aunque, lógicamente, se les atribuyera un halo «ancestral» cuando de litigar tierras prehispánicas se tratara). Legalmente, los indígenas no podían disponer libremente 
de las tierras comunales. A partir de un proceso solo parcialmente explicado para el caso peruano, estos dominios se volvieron, con relativa rapidez, las tierras «ancestrales» o «perpetuas» de cada comunidad (Spalding, 1984: 180-181; Pease, 1986: 15; Stern, 1993: 90; Thurner, 1997: 49). Las antiguas lealtades étnicas se vieron afectadas y los nuevos pueblos y tierras comunales sirvieron de base para la creación de nuevas afiliaciones territoriales e identidades post-reducción. Los miembros de las nuevas «comunidades» pasaron a identificarse crecientemente con uno o más pueblos, sin duda una nueva fuente para la construcción de poderosos sentimientos de pertenencia territorial.

Finalmente, la primera composición general de tierras en la década de 1590 marcó un hito en las transformaciones del sistema de tenencia de la tierra en Huamanga. Buscando limitar la proliferación de «títulos» irregulares y ambiguos, diversos visitadores recorrieron el Virreinato entre 1592 y 1596 con el fin de revisar los títulos existentes. Estos fueron suspendidos hasta que los poseedores pudieran demostrar la legitimidad de sus derechos. Como los españoles, los señores étnicos y las comunidades indígenas también podían comprar de la Corona el derecho de usufructo de tierras vacas. En tales casos, los jueces debían «amojonar» - delimitar, trazar linderos - los terrenos supuestamente vacantes 6 . Sin embargo, la distinción entre tierras comunales y tierras baldías no fue siempre sencilla o conveniente de trazar. A pesar de que, en teoría, los jueces debían proteger los terrenos indígenas de posibles usurpadores, los títulos de la composición solo avivaron los conflictos por tierras. Las apropiaciones de facto pusieron en evidencia las jurisdicciones y los derechos superpuestos que habían venido cobrando forma desde la fundación de la ciudad. Entre 1594 y 1600, vecinos de Huamanga, labradores españoles, mestizos y mulatos, esclavos fugitivos, monjas y sus mayordomos, indios forasteros, antiguos mitimaes y señores étnicos locales intentaron sacar ventaja de las nuevas oportunidades abiertas por el proceso de privatización de la tierra (Prado \& Prado, 1991: passim).

La creciente amenaza de usurpación obligó a las comunidades indígenas a confeccionar títulos y a conducir acciones legales para verlos confirmados. En 1570, por ejemplo, veinte señores étnicos de Huamanga presentaron ante las autoridades una «descripción, modelo y pintura» de sus tierras, «con los árboles frutales, ríos, fuentes, lagunas [y] pueblos». Dentro de la amplia gama de potenciales beneficiarios de la privatización de tierras, tanto los señores étnicos como los llamados indios «ladinos» —indios «aculturados»o «hispanizados»— tuvieron grandes oportunidades de conseguir la posesión exclusiva de la tierra. Las comunidades nativas esperaban que sus curacas actuaran como administradores de las tierras del común, además de representar a sus sujetos en cualquier reclamo legal por la posible usurpación de las mismas.

Sin embargo, la distinción entre reclamos de la comunidad y reclamos de los señores se atenuó tempranamente en el Periodo Colonial (Medelius \& Puente Luna, 2004). Si bien es cierto que muchos señores étnicos batallaron en las cortes para proteger a sus comunidades del despojo de tierras, es igualmente cierto que otros utilizaron su estatus y prominencia para privatizar los antiguos derechos al uso de la tierra, incorporando así ciertos terrenos en su patrimonio personal y familiar. Sus hijos y sucesores heredarían dichos terrenos y defenderían sus derechos de propiedad contra las comunidades indígenas7. Junto con

6 Sobre la primera composición, véase Torres Saldamando, 1888: 89-91; Rowe, 1957: 181. Sobre dicho proceso en la costa norte, véase Ramírez, 1996: 61-76. Sobre la primera composición en Huarochirí y Huamanga, respectivamente, véase Spalding, 1984: 178-182; Stern, 1993: 162-164. Sobre la composición en Cuzco, véase Archivo Regional del Cuzco, 1957: 389-432; Guevara Gil, 1993.

7 Para una discusión general sobre caciques coloniales y la apropiación de tierras comunales, véase Powers, 1995. Para el caso específico de Huamanga, véase la evidencia presentada por Stern, 1993: 162-163. Para un ejemplo de este proceso entre la élite del vecino valle de Jauja, véase AGI, 1713-1717, Escribanía de Cámara, 519B: f. 100v-108r. 
los curacas coloniales, los «indios exitosos», aquellos con «vínculos privilegiados con la estructura de poder colonial» se hallaban en la misma posición privilegiada para privatizar tierras. También en Huamanga, diversos «escaladores sociales» — para usar el término acuñado por Karen Spalding - intentaron transformar sus vínculos con el mundo de los colonizadores, así como su acceso y relativo conocimiento del sistema legal español, en riqueza personal (Stern, 1993: 66, 78, 132-133, 162-164). Así algunos caciques y ladinos también confeccionaron títulos de tierras, aunque siguiendo un propósito distinto, claramente más «individualista»—se nos permitirá usar este término- que el de las comunidades nativas.

A pesar de este escenario innegable de transformaciones, los documentos referidos a litigios de tierras en Huamanga pueden dar la equívoca impresión de que el concepto de «tierra» tenía el mismo significado antes y después de la llegada de los conquistadores españoles. Precisamente por esta razón, los «títulos» prehispánicos constituían un arma tan poderosa en los tribunales: antes que representaciones «transparentes» del pasado prehispánico, su existencia misma se enmarcaba dentro de lo que la justicia española consideraba válido o inválido. La impresión de continuidad emerge de nuestros prejuicios y suposiciones (y los de los jueces coloniales), usualmente guiados por los esfuerzos de los litigantes por acomodar sus derechos e intereses a las profundas transformaciones implícitas en el nuevo panorama colonial.

\section{LA CONFECCIÓN DEL PASADO: MOJONES Y SAYWAS EN LOS TÍTULOS DE GUAMAN POMA}

Las transformaciones históricas sintetizadas en la sección precedente acarrearon múltiples consecuencias para las batallas legales posteriores de Felipe Guaman Poma. Los títulos del cronista a las tierras de Chupas muestran lo que, en su estudio de la colonización del imaginario indígena en Nueva España, Serge Gruzinski (1993: 23) ha denominado la desconcertante «permeabilidad de eras», ese complejo y creativo entremezclarse de historias, personajes y aspectos prehispánicos con acciones, individuos y creencias posteriores a la Conquista. La conquista de Huamanga por el Inca, sus «Concesiones» de tierras a los señores locales y el establecimiento de mojones, todos se combinan con historias acerca del Dios cristiano como dador de tierras («en justo título y posesión» desde que «Dios fundó la tierra», Guaman Poma dixit), los servicios prestados por los nobles ancestros al Rey durante la Conquista, los privilegios concedidos por virreyes y tribunales y las visitas emprendidas por funcionarios en Huamanga.

En efecto, como parte de sus títulos prehispánicos a las tierras de Chupas, Guaman Poma y sus litigantes aliados declararon que los Incas habían reconocido a sus antepasados la posesión de «tierras y mojoneras» en el valle, ordenando que éstas fueran amojonadas para su mejor protección. Los litigantes presentaron una larga lista de mojones que señalaban las tierras familiares. En la Nueva corónica, Guaman Poma también incorporó copiosas referencias a estas saywas o mojones. El texto incluye también una ilustración del supuesto funcionario inca encargado de erigir los mojones en tiempos prehispánicos (el amojonador del reino). De acuerdo con la Nueva corónica, la gente esperaba de estos oficiales que trajeran paz y «civilización» a las «provincias» del Imperio (Guaman Poma, 1992: 111, 114 149, 152, 154, 253, 355, 866, 918; Prado \& Prado, 1991: ff. 54r-55r, 57v, 59v y 65v-66r). A pesar de estas menciones a las saywas familiares, hay que tener en cuenta que los testigos españoles tempranos, así como algunos de los expertos coloniales en asuntos indígenas, no necesariamente mencionan a las saywas como hitos o mojones (en tanto señales para fijar los linderos de chacras u otras posesiones). Algunas saywas funcionaban como pilares para 
sacralizar los caminos y proteger a los viajeros. Otras eran columnas de piedra utilizadas para el cálculo del calendario. Otras saywas eran «de naturaleza conmemorativa o simbólica», sirviendo como marcadores étnicos, dioses y personajes míticos transformados en piedra que recordaban a los distintos grupos sobre sus orígenes y su identidad8.

Típicamente, las historias coloniales acerca de mojones y mojoneras prehispánicos presentan a los Incas como a reyes dadores o usurpadores de tierras, siendo su rol en ocasiones el de «confirmar» los terrenos de los distintos señores étnicos. Sin embargo, la relación entre el Inca, dichos señores y los grupos que estos representaban era de una naturaleza distinta. La temprana obsesión española por identificar las tierras que habían «pertenecido» al Estado inca alimentó una visión distorsionada según la cual los Incas eran dueños de las tierras de un Imperio territorial, permitiendo que las poblaciones conquistadas las usaran a cambio de su subordinación política y del pago de tributo. Investigaciones recientes demuestran que éste no era el caso. Interpretaciones como las precedentes se basaban en lecturas literales de lo que algunos grupos nativos contaron a los jueces españoles con la finalidad de asegurarse tierras supuestamente dadas o confirmadas por los dominadores incas ${ }^{9}$. Escondido tras la terminología judicial española, yacía más bien el hecho que, antes que poseer o dominar tierras per se, los Incas estaban más preocupados por el control de gente y de su fuerza de trabajo, normalmente solicitada a través de los mecanismos rituales y coercitivos de la generosidad institucionalizada (Bandera, 1965: 179; Murra, 1980a; 1980b: 284).

Algunas tareas requeridas por el Estado inca consistían en trabajar determinados campos de cultivo. Dado que cada soberano inca debía renovar y negociar sus lazos políticos y económicos con los grupos subordinados, y en tal sentido cada emperador forjaba su propio Imperio, los campos trabajados por un grupo para el Inca no eran necesariamente los mismos en todo momento, ni su extensión y límites permanecían inmutables con el paso de cada ciclo agrícola. Algunas saywas prehispánicas definían responsabilidades de trabajo y mano de obra, señalizando los terrenos cambiantes dedicados a la producción para el Inca en un determinado momento. Antes que señales fijas y permanentes de límites territoriales claramente establecidos, sin embargo, estas saywas podían funcionar más bien como dispositivos móviles. Los señores étnicos y los soberanos incas las reubicaban cuando nuevas responsabilidades de trabajo y mano de obra habían sido negociadas. La impresión dejada en las fuentes coloniales es, sin embargo, que los Incas estaban entregando tierras y señalizándolas mediante saywas o mojones. En realidad, los soberanos del Cuzco estaban reasignando cuotas de trabajo agrícola10.

Como en muchos otros casos, los españoles «tradujeron» saywas por mojones, confusión de la cual algunos andinos supieron sacar ventaja rápidamente. Mojón era el término español para designar un conjunto de rocas, una cruz o cualquier otro artefacto que sirviera para marcar límites y linderos de tierras —en un sentido aproximado al que se

8 Sobre saywas y mojones, véase Polo de Ondegardo, 1906; Romero, 1919: 183; Arriaga, 1999; Taylor, 1999; Kumai, 2002 y, sobre todo, Ramírez, 2005: 43-45.

9 Aunque muy complejo, el análisis de Nathan Wachtel (1982) sobre los mitimaes del valle de Cochabamba constituye un buen ejemplo. Amparado en lo que los caciques y algunos españoles interesados declararon a las autoridades en un litigio producido varias décadas después de la Conquista, Wachtel presenta el «reparto de tierras» del Inca Huayna Cápac entre aproximadamente 14000 mitimaes a partir de una visión que concibe las «chacras», los «suyos» y los «urcos» como tierras «estatales» o «privadas». Para analizar el caso en mayor profundidad, habrá que esperar la publicación íntegra de los documentos referidos a este caso.

10 Para los dos párrafos precedentes, véase Murra, 1980a: 32; 1980b: 284; Pease, 1986: 30-31; 1992; Ramírez, 2005 : 34. Numerosos ejemplos de la dinámica inca reconstruida aquí pueden encontrarse en fuentes primarias publicadas como Bandera, 1965: 179; Crespo, 1974: f. 4r-5r; Rostworowski, 1988: ff. 149r, 183v, 211r-211v, 316r, 396v. 
le da hoy-. El establecimiento de mojones (amojonar) constituyó un temprano esfuerzo por establecer límites más o menos fijos y bien determinados. En las comunidades andinas contemporáneas, la importancia vital de las caminatas rituales por los linderos y mojones, así como las ceremonias de «recorreo» y «amojonamiento», es innegable (Isbell, 1985: 57 y ss.; Radcliffe, 1990; Abercrombie, 1998; Beyersdorff, 2002; 2005). Sin embargo, antes que confirmar una supuesta continuidad entre las prácticas prehispánicas y las modernas, estas ceremonias nos indican lo contrario: la importancia que rápidamente cobró para los indígenas coloniales el apropiarse de las nociones españolas sobre la tierra (incluidos los mojones), para litigar con éxito en los tribunales coloniales y asegurar tanto la supervivencia de la comunidad como la preservación de sus terrenos. Es muy sintomático que mojón fuera el término predominantemente utilizado por Guaman Poma en sus reclamos de tierras, siendo pues un individuo nacido después de la Conquista, así como un hábil asistente del juez visitador de tierras durante la primera composición ${ }^{11}$. En tal sentido, el famoso dibujo de los «amojonadores del reino» incluido en la Nueva corónica, antes que describir una situación prehispánica, nos presenta algunas de las ideas y percepciones (coloniales) de Guaman Poma acerca del espacio, la territorialidad y el amojonamiento de tierras y linderos en Huamanga.

En efecto, algunas innovaciones muy importantes favorecieron la temprana reinvención de las saywas como mojones en dicha región durante el siglo XVI. En los primeros años de existencia de la ciudad, el Cabildo otorgó «tierras» y «estancias» a varios vecinos. La llegada de nuevos colonos españoles incrementó la demanda y dicha corporación hubo de entregar más de cuarenta mercedes adicionales. Algunos beneficiarios comenzaron a vender sus terrenos, medida que avivó las disputas por «linderos» entre propiedades contiguas. El Cabildo se vio entonces obligado a «amojonar», es decir, a establecer los primeros mojones coloniales en el área, con el fin de deslindar las tierras y estancias en propiedad de individuos particulares. En 1546, la ciudad de Huamanga se apropió de «tierras comunes», concediendo un promedio de ochenta hectáreas a cada uno de los dieciocho vecinos más prominentes que las habían solicitado (Ribera \& Chaves, 1965: 125; Rivera Serna, 1966: f. 17r, 20r, 24v, 112r-114r, 119r).

El nuevo status quo mostró a los grupos étnicos locales la importancia de los mojones a la usanza oficial española. Para poder asegurar tierras y pastos, sus miembros se volcaron rápidamente hacia el paisaje circundante con el fin de identificar, o más precisamente reinventar, algunas características del terreno (lomas, ríos, montes) y artefactos de hechura humana (las famosas saywas) como mojones y señales de supuestos linderos prehispánicos. La fabricación de «títulos» de tierras requería también del apoyo crítico de narrativas acerca del pasado. Estas narrativas, entretejidas con los reclamos legales del presente, incorporaban referencias a híbridos mojones/saywas, Incas generosos y curacas dueños de tierras antes que «dueños de indios» (como los define Susan Ramírez en un trabajo incluido en este volumen). A pesar de esto, algunos mojones, presentados como marcadores prehispánicos de tierras «privadas», escondían aun parte de su naturaleza prehispánica en los nombres con que eran denominados. Tómese, como ejemplo, la lista de mojones presentada por Guaman Poma para reclamar las tierras familiares de Chupas. Antes que claras referencias y marcadores de mojones y mojoneras, los nombres de los mojones aluden más a los elementos del paisaje: urco [cerro, loma], guaico [quebrada entre cerros], pata [grada, andén], pampa [llanura] y mayo [río]. Entre muchas otras funciones, cerros, lagos, ríos, caminos y canales podían efectivamente delimitar los linderos de chacras prehispánicas. Operando bajo una lógica

11 Sobre la actuación de Guaman Poma como intérprete y asistente del juez Gabriel Solano de Figueroa en Huamanga, conocida desde hace décadas, véase Stern, 1978; Pereyra, 1997; Varallanos, 1979: 210-211. 
distinta, sin embargo, estos límites no eran líneas claramente definidas, sino más bien puntos de referencia relativamente imprecisos, marcadores de tareas y responsabilidades agrícolas usualmente compartidos por varios grupos étnicos. Combinados con hitos de hechura humana, sin embargo, estos marcadores eran capaces de alimentar poderosos argumentos legales al momento de reclamar tierras en Huamanga colonial12.

En suma, hacia 1590, los mojones habían terminado adquiriendo un nuevo y engañoso significado, el cual emerge claramente en los litigios por tierras de Felipe Guaman Poma. A pesar de evocar muy vagamente algunas de las antiguas funciones desempeñadas por las saywas prehispánicas, los mojones coloniales eran parte en realidad de un conjunto de tradiciones inventadas sobre la «tierra» en la Huamanga del siglo XVI. «Antiguas» tradiciones acerca de los Incas como dadores, usurpadores o confirmadores de tierras — dependiendo de qué buscaran probar los litigantes - sirvieron como materia prima para confeccionar estas historias13. Hacia 1590, un «motivo» típicamente andino-colonial para reclamar tierras había emergido finalmente en Huamanga. Todos los títulos de tierras asegurados durante el temprano Periodo Colonial — fuera por descendientes de los incas o por cualesquier otros grupos - siguieron más o menos la misma lógica. Los «títulos» de Guaman Poma a las tierras de Chupas no eran únicos en este respecto, a pesar que, quizás influidos por la importancia del cronista, hayamos querido darles un trato diferente.

Las ideas anteriores no buscan afirmar que títulos de tierras como los de Guaman Poma no son importantes para la comprensión de las sociedades andinas coloniales. Muy por el contrario, y debería resultar obvio para este momento, su relevancia histórica reside precisamente no en su «exactitud» para referir personajes, acontecimientos y territorios prehispánicos, sino más bien en su naturaleza híbrida como artefactos coloniales producidos por mentes andino-coloniales. El arte legal de confeccionar títulos para legitimar reclamos de tierras y confirmar supuestos derechos ancestrales a un territorio circunscrito - arte que Guaman Poma había logrado dominar en la década de 1590 - combinaba elementos de tres «repertorios» distintos, tres fuentes paralelas de legitimidad jurídica: el pasado preincaico, el dominio incaico y la Conquista española. Cuestionar la «verdad» contenida en los títulos no es sugerir ingenuamente que las poblaciones andinas, o Guaman Poma para tal caso, «mintieron» en los tribunales coloniales o engañaron a los jueces de tierras. El problema es mucho más complejo, pues distintas visiones de la tierra y del territorio pueden coexistir en un individuo o grupo, emergiendo de acuerdo con las necesidades planteadas por el contexto (religioso, legal, económico, etc.).

Guaman Poma escribió y litigó más de sesenta años después de la Conquista. Los mojones «a la usanza española» eran probablemente los únicos que llegó a conocer, especialmente durante su activa participación en la primera composición de tierras en Huamanga, como veremos. En tal sentido, sus títulos no son otra cosa que una poderosa muestra de la enorme capacidad de adaptación y transformación de la cultura andina, así como el resultado de su visión altamente aculturada y colonial —no por eso menos andina- del mundo prehispánico. El cronista intentó presentar los mojones familiares como parte de una tradición autóctona, identificada con el orden y la civilización inca, y por tanto con el mundo de justicia y jerarquías tradicionales que buscaba ver «restaurado» en su proyecto de buen gobierno. A pesar de esto, y sin negar el profundo conocimiento que el cronista tenía de muchos aspectos de la cultura andina, no es válido asumir, en este caso, que el punto de vista de Guaman Poma en los acontecimientos reconstruidos aquí representa el «punto

\footnotetext{
12 Para las traducciones, véase González Holguín, 1952: 191, 236, 275, 281 y 357.

13 Para un caso análogo, el de los mapas y «títulos primordiales» en Nueva España, véase Lockhart, 1983; 1985; Leibshon, 1994; 1995; Gruzinski, 1993.
} 
de vista» indígena prehispánico que tanto ha buscado aprehender la etnohistoria andina. Al menos, no representaba el de aquellas comunidades indígenas que aún operaban bajo patrones tradicionales de acceso a los recursos y que tuvieron que lidiar con el fenómeno de apropiación de tierras a manos de curacas, españoles e indios ladinos (hasta que, por supuesto, el orden colonial obligara a dichas comunidades a producir sus propios «títulos»). Tal como se desprende de los documentos generados por su litigio de tierras, el punto de vista del cronista en este respecto emanaba de una lógica más individualista, la cual perseguía obtener la posesión privada de determinadas tierras. En una especie de paradoja, si Felipe Guaman Poma alguna vez tuvo la oportunidad de asegurar derechos exclusivos a las tierras de Chupas, tales derechos solo pudieron cobrar forma en el «mundo al revés» que tan vehementemente denunció en la Nueva corónica.

\section{SEÑORES ÉTNICOS Y LA APROPIACIÓN DE TIERRAS: LAS POSESIONES FAMILIARES EN CHUPAS}

En la discusión precedente —algo extensa pero necesaria para seguir la argumentación hasta este punto- he adelantado algunas ideas, preparando el terreno para una visión alternativa de la famosa tesis de la «desposesión» de las tierras familiares de Chupas. En repetidas ocasiones, Guaman Poma y sus litigantes aliados sostuvieron que habían heredado las tierras, árboles, lomas y mojoneras que reclamaban de don Juan Tingo y don Domingo Guaman Malqui de Ayala, sus nobles ancestros y señores del «valle y pueblo» de Santa Catalina de Chupas. Desentrañar esta afirmación nos lleva al análisis de dos asuntos interrelacionados. Primero, es preciso explorar el estatus de Tingo y de Guaman Malqui en tanto «caciques del Valle y pueblo de Santa Catalina de Chupas», así como el significado histórico que esta misteriosa jurisdicción pudo tener en la década de 1590. Segundo, es necesario rastrear el desarrollo de los reclamos legales impulsados por los herederos de estos señores, así como la participación tardía pero crucial de Felipe Guaman Poma en las mismas. El análisis detallado de los títulos coloniales a las tierras de Chupas mostrará que la consolidación de las posesiones «familiares» entre 1570 y 1600 siguió el típico patrón de apropiación de tierras a manos de curacas y sus descendientes.

Debido al uso bastante ambiguo del término «Chupas» en la Nueva corónica y el llamado Expediente Prado Tello (el principal legajo de documentos acerca de las tierras familiares en Chupas), el determinar si «Santa Catalina de Chupas» era un asentamiento prehispánico, un pueblo Post-Conquista o la combinación híbrida de ambos, es una tarea compleja. «Chupas» aparece como un valle y su pueblo principal («pueblo medio y cabesa» de Santa Catalina de Rantavilca de Chupas), así como el supuesto cacicazgo territorial de los ancestros del cronista. Las mismas fuentes describen «Chupas» también como una o más lomas e inclusive como una hacienda. Referencias adicionales presentan «Chupas» como un ayllu o parcialidad (Prado \& Prado, 1991: ff. 52v-53r, 54r, 64v, 68r). La coexistencia de estas informaciones no permite ser concluyente, sobre todo porque antiguos y nuevos asentamientos indígenas aún coexistían en Huamanga tras el establecimiento de las primeras reducciones (Ribera \& Chaves, 1965: 184-185).

Este problema, sin embargo, es central para entender la lógica colonial detrás de los reclamos de tierras de Guaman Poma. Algunos autores que han escrito sobre los orígenes familiares y derechos a tierras del cronista han asumido que los «pueblos» asociados con la vida de Guaman Poma en Huamanga (Santa Catalina de Chupas, San Cristóbal de Sondondo, Santiago de Chipao, etc.) eran asentamientos prehispánicos y que, por ponerlo de alguna forma, siempre habían estado allí (Husson, 1995: 51-52, 60-61). Éste fue rara vez el caso. Como las dos secciones anteriores lo demuestran, muchos pueblos en la zona de Huamanga 
no existían propiamente como tales antes del establecimiento de las reducciones, cuando estos comenzaron a servir como fuente de nuevas identidades y lealtades territoriales. Algunos pueblos, llamados usualmente «asientos» o «caseríos» en la documentación de la región, carecían de una fundación española formal. Estimulados por la demanda citadina de mano de obra y otros recursos indígenas, estos asentamientos emergieron más o menos «espontáneamente» tras la Conquista y las tempranas guerras civiles (Espinoza Soriano, 1978). Esto fue lo sucedido con Santa Catalina de Chupas, donde los Chachapoyas y luego Guaman Poma (o sus supuestos parientes) construyeron casas e iglesias en las décadas de 1580 y 1590. Algunas fuentes mencionan Chupas como un «asiento» en 1540 y como un «pueblo» (¿un grupo de gente?) en 1543. Así, es plausible suponer que Chupas no tuvo una fundación oficial como reducción (Vaca de Castro, 1908: 445; Morote, 1975: 10; Zorrilla, 1977: ff. 24v-26r).

Pueblos «espontáneos» como Santa Catalina de Chupas exhibían una configuración social muy compleja, con viejas y nuevas poblaciones, así como varios señores y sus sujetos viviendo bajo los nuevos patrones españoles de organización política y de uso de la tierra. El Expediente parece revelar que la expresión «valle y pueblo de Santa Catalina de Chupas» aludía en realidad a un pueblo colonial cuyas tierras circundantes habían estado antes «abiertas» y habían sido compartidas por varios grupos étnicos (Prado \& Prado, 1991: ff. 53r54v). A pesar de los reclamos constantes de Guaman Poma sobre la posesión exclusiva de dichas tierras, en 1570, el mismo don Juan Tingo, supuesto antepasado del cronista, se había presentado a sí mismo sólo como «principal» en Chupas, es decir, como una autoridad de bajo rango entre otras viviendo en el asentamiento. Tingo y sus súbditos todavía compartían aquellos campos de Chupas con grupos también establecidos allí, aunque con un grado cada vez mayor de conflictividad (Prado \& Prado, 1991: ff. 60v-61r).

En uno de los famosos dibujos incluidos en el Expediente, el pueblo de Chupas aparece al centro del Valle, en un área rectangular claramente delimitada por mojones a la usanza española14. Vale la pena detenerse en el dibujo por un momento. Como en el caso de los títulos «prehispánicos», esta descripción gráfica del curacazgo de los ancestros Tingo y Guaman Malqui, así como su supuesta jurisdicción sobre todo el valle (sus «tierras, arboledas, lomas y mojoneras») presenta un típico paisaje colonial, con muy poco significado en términos de los antiguos curacazgos prehispánicos. En efecto, cuando términos como «cacicazgo» o «pueblo» fueron utilizados por señores étnicos y otros nativos en los primeros tiempos coloniales, casi siempre querían significar «gente» —normalmente dispersa en el territorio - antes que un lugar claramente delimitado, una provincia o cualquier otra entidad territorial (Ramírez, 1996; 2005). Pero los filtros culturales españoles primero deformaron y luego actuaron sobre la configuración andina previa, representando grupos étnicos fijos en el territorio. Estos señoríos territoriales coloniales no eran otra cosa que el resultado gradual de las propias innovaciones españolas en las organizaciones políticas prehispánicas (innovaciones que se combinaron con la aceptación y posterior manipulación de estos conceptos por parte de los indígenas). Gradualmente, los curacas se convirtieron en señores de entidades políticas y administrativas previamente inexistentes — las reducciones-. En este largo y complejo proceso, algunos grandes curacas perdieron poder, mientras que otros de menor jerarquía aprovecharon la situación y expandieron su jurisdicción sobre

${ }^{14}$ Se trata de una copia del siglo XVII, por lo que lo único que se puede asumir con cierta seguridad es que, en sus rasgos generales, y más allá de los detalles precisos, este dibujo reproduce las características más importantes del dibujo original, ahora perdido. Como lo han sugerido varios investigadores, es casi seguro que éste y los otros originales (las representaciones de don Domingo Guaman Malqui y don Juan Tingo) fueron elaborados por Guaman Poma. 
nuevos sujetos, nuevos asentamientos y nuevos territorios, como el mismo Guaman Poma lo refiere en varios pasajes célebres de su obra15.

Así, para la década de 1590, indios y españoles de Huamanga ya habían traducido los antiguos curacazgos andinos y sus jurisdicciones sobre poblaciones dispersas como unidades territoriales, una nueva concepción altamente favorecida por la primera composición y la necesidad de confeccionar títulos. Los cacicazgos se estaban convirtiendo rápidamente en una especie de dominio territorial sobre uno o más pueblos (no necesariamente sus habitantes), y esto es precisamente lo que Guaman Poma parece presentarnos en sus esfuerzos por asegurar derechos exclusivos sobre el valle de Chupas. En tal sentido, los reclamos de los indios Chachapoyas, los cuales han sido normalmente pasados por alto por los estudiosos del tema, son muy sintomáticos. En 1600, los Chachapoyas denunciaron «Santa Catalina de Rantavilca» como un falso cacicazgo, un curacazgo no existente cuyo supuesto cacique - Felipe Guaman Poma - no era más que un impostor sin verdaderos súbditos: un cacique sin cacicazgo (Zorrilla, 1977: ff. 24r-25v). Así, incluso si don Juan Tingo y don Domingo Guaman Malqui tuvieron una cuota de jurisdicción y autoridad étnica sobre algún grupo viviendo en el valle, es obvio que nunca controlaron un área territorial continua y claramente delimitada, con el pueblo de Chupas como centro, ni gobernaron sobre un señorío territorial como el que presentaron sus descendientes en el Expediente16.

Al igual que los chachapoyas, considerados tradicionalmente como los usurpadores de las tierras del cronista, don Domingo Guaman Malqui y don Juan Tingo no eran señores «locales», sino líderes de grupos de mitimaes, linajes incas no pertenecientes ni a la realeza ni a la nobleza, establecidos en Huamanga antes de la Conquista o inmediatamente después de la misma. Don Juan Tingo era un miembro prominente de los cavinas («parsialidad de Congachuri Caviña»). Otro de los litigantes, Martín de Ayala (posiblemente descendiente de Domingo Guaman Malqui de Ayala) era un «principal Andamarca» o simplemente «Anda»17. Los primeros colonizadores españoles habían fundado Huamanga en tierras ocupadas por el «pueblo y parcialidad» de los Andas (Monzón, 1965a: 227-230, 232; 1965b: 237-248), una decisión que probablemente favorecería los reclamos futuros de Martín de Ayala a algunos de los terrenos cercanos a la ciudad. La posición relativamente privilegiada de Ayala, combinada con el hecho que en tiempos de la dominación inca los ancestros de don Juan Tingo habían expulsado a los angaraes del valle vecino de Chupas, dieron cierta legitimidad a los reclamos de los herederos de ambos señores. Sin embargo, no debe olvidarse que tales «derechos» a tierras fueron también esgrimidos por otros grupos étnicos «locales»y «forasteros», conquistadores y conquistados, supuestos usurpadores y supuestos despojados18. Todos estos grupos, dependiendo de su situación particular, sustentaron sus

15 Para un ejemplo típico en el vecino valle de Jauja, véase AGI, 1570-1600, Lima, 136.

16 Para el caso del vecino valle de Jauja, por ejemplo, la transformación colonial antes descrita se evidencia en el uso del vocablo «repartimiento» — cada vez más con una connotación territorial continua- y en la ausencia de términos como «cacicazgo» para hacer alusión a la jurisdicción de los señores étnicos. De forma similar, la transformación se anuncia también en el empleo aleatorio y ambiguo de los plurales «Luringuancas» y «Jauxas» para referirse a las comunidades humanas que, ya para ese entonces, estaban siendo confinadas cada vez más a vivir en el territorio de los repartimientos de «Luringuanca» y de «Atunjauja», respectivamente. Con el tiempo, la segunda acepción — la del territorio — triunfaría sobre la primera — la de la comunidad—. Véase Puente Luna \& Solier Ochoa, 2007.

17 Véase Prado \& Prado, 1991: ff. 51r, 55v, 60v-61r; Guaman Poma, 1992: 415-422. Para los antas y cavinas, véase Levillier, 1940: 41, 45; Zuidema, 1967: 72-73; Pärssinen, 1992: 269.

18 En 1593, por ejemplo, algunos indios aymaraes del pueblo de Chuschi reclamaron que los indios canas les estaban usurpando unas tierras entregadas por Túpac Inca Yupanqui. Los canas presentaron un supuesto auto de Damián de la Bandera en que se reconocía que habían sido trasladados a la zona de Huamanga por el Inca Huayna Cápac. El corregidor les adjudicó 10 topos de tierras. El documento en cuestión, perteneciente al archivo de la comunidad de Quispillacta, ha sido transcrito por Isbell (1985: 65 y 247-248). 
reclamos en la combinación específica de determinados libretos preincaicos, incaicos y coloniales, fabricando así títulos «válidos» de tierras en Huamanga.

A pesar de la historia contada por los litigantes aliados del cronista, es preciso buscar el origen de los títulos de Tingos y Ayalas en las mercedes del Cabildo de Huamanga durante la década de 154019. En ese lapso, al menos cuatro curacas recibieron «títulos» a los campos que sus súbditos cultivaban en Chupas. Algunos españoles también aseguraron títulos a campos agrícolas y pastos en la misma área. Más importante aún, el Cabildo ordenó la adjudicación de varios terrenos a grupos locales y mitimaes en Chupas, por lo que las autoridades concedieron ciertos campos a Juan Tingo y a los cavinas, entre otros, a comienzos de la década de 1540 (Guaman Poma de Ayala, 1992: 415; Rivera Serna, 1966: 19r-19v, 21v, 65r, 70v, 73v; Espinoza Soriano, 1978: 238; Varallanos, 1979: 28, nota 21). Es altamente probable que, como muchos otros vecinos españoles, los encomenderos de los cavinas hayan solicitado la entrega de ciertas tierras para sus encomendados durante las dos décadas siguientes, una modalidad bastante extendida para asegurarse la mano de obra y el tributo indígenas (AGI, 1548-1595, Patronato, 95B, r. 8: ff. 20-23; AGI, 1596-1601, Lima, $199,18)^{20}$. Tanto las mercedes del Cabildo, cuanto las tierras concedidas al encomendero de los Cavinas, pueden aludir entonces a uno de los primeros títulos esgrimidos por Guaman Poma ante los tribunales.

Adicionalmente, el análisis detallado de los títulos posteriores de Tingos y Ayalas muestra que los mismos siguen el patrón común de apropiación y privatización de tierras por descendientes de señores étnicos prehispánicos. La historia de estos pleitos legales tiene dos fases. La fase pre Guaman Poma, entre 1586 y 159621, involucra a litigantes iniciales como Martín e Isabel de Ayala, e Inés Coca y Alonso Guamani, probablemente los verdaderos descendientes de Juan Tingo y Guaman Malqui de Ayala. Felipe Guaman Poma —quien, sintomáticamente, no parece utilizar el «De Ayala» todavía — está ausente en este periodo inicial, ocupado como estaba asistiendo al visitador de tierras y juez designado en Jauja y Huamanga (Puente Luna \& Solier Ochoa, 2007). En contraste con la fase guamanpomiana, entre 1597 y 1600, los litigantes Tingos y Ayalas iniciales, más modestos y menos hábiles en sus demandas que su famoso futuro aliado, ni reclamaron todo el valle de Chupas para sí ni manufacturaron «derechos ancestrales» a las tierras de forma tan elaborada como Guaman Poma. Estos litigantes solo reclamaron ciertas tierras y arboledas, consiguiendo asegurar sus derechos a ellas. Tampoco tuvieron la habilidad suficiente para elaborar las peticiones y los memoriales ellos mismos (como lo haría Guaman Poma), por lo que recurrieron a la ayuda del protector de naturales. Solo después que los Tingos y Ayalas hubieran asegurado títulos a sus tierras en 1594-1595, y debido a las numerosas «intromisiones» de los indios Chachapoyas y de otras personas que ya habitaban el valle de Chupas, «Don Phelipe Guamanpoma» aparece en esta historia, representando al clan cuyos derechos habían sido supuestamente vulnerados. Su participación inicial se caracterizó por la elaboración y presentación de largos y complejos memoriales (algunos ilustrados) ante la Audiencia de Lima y luego ante

19 Sobre mercedes hechas a encomenderos por los cabildos de Lima y Cuzco, véase Wachtel, 1977: 100-101.

20 Estas cesiones iniciales de tierras explicarían por qué Guaman Poma y sus litigantes aliados mencionan al encomendero Cristóbal Peña y a sus herederos como vecinos cercanos en Chupas, poseedores de los campos adyacentes a las supuestas tierras familiares del cronista, así como «intrusos» en dichas tierras. La temprana entrega de tierras por el Cabildo, así como los derechos superpuestos, títulos ambiguos y vagos linderos, enfrentarían a los herederos del capitán Peña con los descendientes de Juan Tingo en la década de 1590, cuando ambas partes trataran de apropiarse de los terrenos que habían estado usufructuando en Chupas (Prado \& Prado, 1991: f. 22r, 61v).

21 Una lectura atenta de $Y$ no ay remedio muestra que, si bien algunas de las tierras de Chupas habían estado en litigio desde la década de 1580 o incluso antes, la participación de Guaman Poma como litigante se inicia recién en 1596 y no antes (1586), como los autores que han seguido el trabajo fundacional de Rolena Adorno (1993) han venido aseverando. Véase, por ejemplo, Chang-Rodríguez, 1995: 100, 110-111; 2005: 55-56. 
la justicia local en Huamanga. La poderosa pluma del futuro autor Ayala transformó los limitados reclamos iniciales en los altamente elaborados «títulos» prehispánicos y coloniales al valle y pueblo en Chupas (analizados en la sección precedente), efectivos artefactos legales hábilmente modelados para causar un gran impacto ante la justicia virreinal.

Dejando de lado el problema de la identidad del cronista como verdadero descendiente de don Domingo Guaman Malqui de Ayala, la razón principal para su participación en estas batallas legales debería resultar evidente: el intérprete y asistente indígena del juez visitador de tierras, aquella persona a cargo de dirimir disputas por linderos y conceder títulos de tierras, se había vuelto un experto en estos asuntos. La experiencia vital de Guaman Poma al lado de visitadores coloniales era de larga data. Respecto de la influencia de la institución de la visita en el cronista, Adorno ha escrito que se trató de una «guía» o «modelo» para el cronista, una experiencia «abarcadora» y «penetrante» que informó toda su obra 22. Sin embargo, hay que tener presente que, incluso desde su gestación, los objetivos de la inspección eclesiástica de Cristóbal de Albornoz a la cual se refiere prioritariamente Adorno, diseñada para combatir los cultos autóctonos, fueron de índole muy distinta de los de la primera composición general, preparada en cambio para sembrar orden en los «títulos» de tierras. Otros puntos de vista del cronista, sobre todo en lo referido a la propiedad individual de la tierra y a los títulos coloniales a la misma, merecen también atención. La misma Rolena Adorno ha señalado que «la penetración de la visión de los visitadores en la mentalidad de los indios ladinos que los servían merece estudiarse más a fondo». Así, el análisis de su experiencia con Solano de Figueroa resulta crucial para avanzar nuestro conocimiento acerca de otros aspectos de la mentalidad de Guaman Poma.

Durante su relativamente corta carrera como asistente e intérprete del juez en Jauja y Huamanga, Guaman Poma fue testigo de excepción de la importancia de los mojones y títulos prehispánicos para las poblaciones indígenas cuando de asegurar tierras ante la justicia se trataba. El cronista presenció también los esfuerzos y las estrategias de señores étnicos e individuos particulares por obtener terrenos privados y comunitarios. En Jauja, fue testigo de excepción de las disputas por linderos que enfrentaron a dos grupos étnicos que, a la manera del cacicazgo territorial de Chupas, intentaron presentar sus respectivos cacicazgos como unidades territoriales con fronteras claramente delimitadas y conseguir así las chacras en disputa (Puente Luna \& Solier Ochoa, 2007). Pocas semanas después, en septiembre de 1594, Guaman Poma se desempeñó como intérprete mientras el juez dio ciertos títulos de tierras a un grupo de nativos. Solo cuatro días después, el mismo Guaman Poma condujo una inspección de tierras como delegado del visitador, estableciendo los linderos y amojonando dichos terrenos. Con su trabajo, aseguró la posesión exclusiva de las tierras para una mujer indígena que decía haberlos heredado. En noviembre del año siguiente -1595- lo vemos aparecer otra vez. En esta oportunidad no solo actuó como intérprete, sino también como testigo, cuando el juez visitador concedió ciertas tierras a título personal y exclusivo a los herederos de un curaca local (Zorrilla, 1977: 50, nota 1; Pereyra, 1997: f. 5r; Varallanos, 1979: 210). Solo después de adquirir toda esta experiencia judicial, dominar los argumentos legales relevantes y familiarizarse con las distintas fuentes de legitimidad (preincaica, incaica y colonial) para reclamar tierras exitosamente en el mundo virreinal, Guaman Poma participó directamente en las batallas legales por las famosas tierras de Chupas.

22 De esta experiencia, el cronista derivó algunos de sus puntos de vista sobre las religiones indígenas y sus practicantes, por ejemplo. Otros efectos de la experiencia de la visita en el autor y la obra pueden detectarse en los capítulos dedicados a la visita de Tupac Inca Yupanqui, en las categorías de edad de las poblaciones andinas y en la organización interna del buen gobierno, así como en la voluntad del cronista de presentarse como visitador experimentado para reforzar su autoridad. Véase Rowe, 1958; Adorno, 1987: xvii-xlvii; 1991; 2000: xlvii, li-liii; 2001: 41-43, 46; Murra, 1992b: 60 y ss.; Chang-Rodríguez, 1995. 
Durante la fase anterior a la participación del cronista, los Tingos y Ayalas presentaron dos títulos a chacras y arboledas en el área de Chupas, uno fechado en 1570 y el otro, en 1587. Efectivamente, en abril de 1587, Inés Coca había reclamado sus derechos a ciertas chacras, árboles e, incluso, una acequia que decía habían pertenecido a su padre, el difunto señor Cavina don Juan Tingo. En esta ocasión, el éxito legal de Inés dependió de la presentación del otro título, anterior y fechado en junio de 1570. Este título inicial «probaba» la posesión de Tingo de dichos árboles y chacras. Sin embargo, una lectura más atenta del título de 1570 muestra que Tingo, como muchos otros señores étnicos que tuvieron que hacer frente a los crecientes conflictos por tierras, solo había solicitado al corregidor la protección de determinadas chacras de coca al este de Chupas, pedido que las autoridades coloniales terminaron por atender (Prado \& Prado, 1991: ff. 60r-61v).

Buscando proteger los recursos del grupo, Tingo no había actuado a título personal sino en nombre de los miembros del ayllu Cavina, hecho que no debe pasar inadvertido. Su empresa colectiva, sin embargo, representaba ya una sutil innovación colonial. Es cierto que un grupo prehispánico tenía derechos exclusivos a aquellos arbustos de coca cuyos miembros habían cultivado, y éste parece haber sido el caso de Tingo. Sin embargo, carecía de sentido, bajo la lógica predominante de usufructo de la tierra, reclamar derechos de ese tipo a los terrenos sobre los cuales dichos arbustos habían crecido (Rostworowski, 1988). Comenzando a razonar tal como lo harían sus descendientes dos décadas después, sin embargo, Tingo aseguró los terrenos para su grupo Cavina. Siguiendo esta misma lógica, y dando el paso siguiente, Inés Coca y sus socios legales consiguieron la posesión de los cocales en 1586-1587. El reclamo inicial de Tingo constituye el «título» más antiguo a partir del cual sus descendientes construirían sus reclamos a todas las tierras y arboledas que supuestamente habían pertenecido al señor étnico (mas no necesariamente a su grupo, elemento ausente), en Chupas y en los alrededores. Así, la historia de los cocales de los cavinas ilustra los inicios del mecanismo a partir del cual los Tingos y Ayalas procederían en la década de 1590.

En enero de 1595, Inés Coca y Martín de Ayala recurrieron una vez más a la justicia virreinal. En esta ocasión, buscaron la protección del juez visitador de tierras. Recurriendo otra vez a los «títulos» heredados, Coca y Ayala denunciaron que algunos encomenderos, los señores étnicos de un poblado cercano y el mayordomo de un convento local les estaban usurpando sus chacras y sitios de Andas y Rantavilca, en Chupas. Los campos incluían numerosos árboles, valioso recurso que los invasores estaban extrayendo para su beneficio (Prado \& Prado, 1991: f. 61v). Las investigaciones del visitador establecieron que, efectivamente, el administrador de las monjas de Santa Clara había cortado más de 100 árboles. En su defensa, el administrador alegó, muy sintomáticamente, que se había tratado, al menos hasta entonces, de bosques considerados abiertos y comunes.

Sin embargo, Martín de Ayala, quien recurrió a títulos familiares previos, reclamó la leña para sí. El juez visitador - iquizás influido por su asistente e intérprete, Felipe Guaman Poma?- ordenó al mayordomo que pagara a los supuestos dueños por la madera. Casos análogos dan cierto sustento a los reclamos de Ayala, pues está documentado que, como en el caso de la coca, los grupos étnicos habían gozado de derechos a los árboles por ellos plantados (Rostworowski, 1988; Ramírez, 1996: 60). Sin embargo, los sitios de Andas y Rantavilca reclamados por Martín de Ayala no solo incluían arboledas, sino también árboles y bosques comunes que no eran «poseídos» bajo las pautas prehispánicas. Bajo el sistema anterior, distintos grupos se habían beneficiado del uso común y abierto de recursos como bosques y pastos naturales. Pero incluso más interesante fue lo que finalmente sucedió con las tierras sobre las cuales los árboles en disputa habían crecido. Entre julio y agosto de 1595, el juez visitador confirmó los derechos exclusivos de Inés Coca y de Martín de 
Ayala, no solo a dichos árboles, sino también al sitio de Andas, sus «tierras y chacras» (Prado \& Prado, 1991: f. 62v). Reclamando los árboles, Inés Coca y Martín de Ayala habían finalmente asegurado la tierra.

La famosa disputa entre Tingos y Ayalas, de un lado, y los chachapoyas, por otro, aporta el ejemplo final de este proceso de apropiación privada de tierras. A pesar de haber sido sobredimensionada en estudios anteriores, la batalla legal por la loma de Chiara era solo una pequeña porción del escenario más amplio. Los chachapoyas —no más de veinte o treinta familias - eran solo uno de los muchos «intrusos» denunciados por Guaman Poma y sus socios legales como usurpadores de las tierras familiares de Chupas. En una petición fechada en 1594, Inés Coca y Martín de Ayala aseguraron títulos exclusivos a las lomas de Chiara y Rantavilca, presentadas hábilmente como parte del cacicazgo de sus ancestros (Prado \& Prado, 1991: f. 60v). Para sustentar sus derechos, los solicitantes presentaron los mismos títulos dados a Inés Coca en 1587 (discutidos líneas arriba). Sin embargo, en dicha ocasión - anterior a la intervención de Guaman Poma en la disputa- Inés solo había reclamado para sí una lista de chacras de maíz y papa, es decir, tierras cultivadas, cosechas provenientes del trabajo sobre la tierra, no la tierra per se. Dichas chacras habían pertenecido a su padre y algunas de ellas llevaban el nombre de «Chiara» y «Rantavilca».

Años después, las autoridades coloniales notificaron a los chachapoyas y a otros personajes que habían venido usando los campos de Chiara que se encontraban, de súbito, ocupando ilegalmente las tierras pertenecientes a Inés Coca. Representados por sus caciques, los chachapoyas se negaron a abandonarlas. Alegaron que las habían estado utilizando, junto con los árboles circundantes, desde la década de 1540, siempre con el conocimiento del señor Cavina don Juan Tingo y luego, con el de su hija Inés Coca. Adicionalmente, cuando en 1586 los señores Chachapoyas aseguraron títulos a las mismas tierras de Chiara para sus súbditos (las que estaban ahora en disputa), alegaron coincidentemente que las tierras no habían estado en uso por más de cincuenta años, circunstancia que el juez de tierras verificó antes de darles la posesión de la loma en cuestión (Zorrilla, 1977: ff. 2r-2v, 8r). Esta argumentación, presentada por los señores Chachapoyas, aludía a la distinción crucial entre la temporal ocupación y jurisdicción de tierras antes en desuso, por un lado, y la relativamente novedosa posesión exclusiva de tierras independientemente de su uso efectivo, por otro.

Además, los chachapoyas sostuvieron que Tingo no se había opuesto a que ellos y otros individuos sembraran sus propias chacras en Chiara siempre y cuando se le entregara a cambio una cuota de mano de obra, la misma que los chachapoyas proveyeron para la construcción de canales en la recientemente fundada Huamanga (Prado \& Prado, 1991: f. 60v). Se trataba, efectivamente, de un arreglo documentado en otras circunstancias. Señores étnicos prehispánicos y del temprano Periodo Colonial no se habían opuesto a que los súbditos de otros señores trabajaran los campos que ellos no estaban usando, especialmente cuando aquellos requerían mayor fuerza de trabajo que la que sus súbditos podían proveer. Ambas partes se beneficiaban de tal situación, pues los «forasteros» aseguraban el uso de determinados campos mientras que los «anfitriones» recibían a cambio mano de obra o una parte de lo producido en dichos campos (Rostworowski, 1988: 84v; Ramírez, 2005: 41-42).

En suma, los cavinas (sujetos de Tingo) y los chachapoyas habían estado cultivando intermitentemente la loma de Chiara en algún tipo de acuerdo, bastante precario, por cierto. La armonía entre ambas partes se deterioró tras la muerte del señor Cavina, cuando sus herederos entraron en la escena. Acorde con los nuevos tiempos, ambos bandos comenzaron a confeccionar títulos a los recursos previamente compartidos. Aunque es un hecho normalmente pasado por alto, tanto los chachapoyas, como Inés Coca, consiguieron 
títulos de la justicia virreinal a las mismas tierras y en los mismos años, 1586 y 1595 (Zorrilla, 1977: ff. 5r-5v, 13v-14v, 25v; Espinoza Soriano, 1978: 242; Prado \& Prado, 1991: ff. 60r$61 v)$. Más que una confusión colonial, la proliferación de títulos ambiguos y de jurisdicciones superpuestas es quizás la mejor prueba de que varios grupos habían compartido los campos de Chupas en una coexistencia no siempre armoniosa, bajo una racionalidad que venía volviéndose obsoleta rápidamente. Es probable que los chachapoyas hubieran llegado a la zona después de los cavinas. No se trata, sin embargo, de un argumento válido para reclamar la primacía de unos sobre otros (argumentación propia de la interpretación vigente). Ninguno de los dos grupos podía reclamar derechos exclusivos a los terrenos bajo el viejo sistema, no porque ambos fueran mitimaes en último término (muchos mitimaes aseguraron títulos de tierras en el Periodo Colonial), sino porque tal opción solo fue posible tras el impacto de las profundas transformaciones que afectaron a estos grupos y a su entorno luego de la Conquista ${ }^{23}$. ¿Por qué asumir, entonces, a partir de la interpretación vigente, que los derechos de los herederos de Tingo eran más legítimos que los de los chachapoyas y, por tanto, los primeros fueron víctimas de una usurpación? Sin duda, ambos bandos intentarían solucionar la creciente disputa adaptando los dos sistemas opuestos de uso de la tierra, así como recurriendo a la función mediadora del sistema legal español. Nuestras simpatías implícitas por uno de los bandos de la disputa, sin embargo, emergen de nuestra visión actual de los actores involucrados en esta historia, una interpretación en gran medida impuesta sobre la realidad en que dichos actores se desempeñaron.

Durante los años que duró esta batalla legal por la loma de Chiara, una diferencia sutil pero muy importante podía percibirse aún entre la lógica y la naturaleza detrás de los intereses de ambas partes. La misma merece un último comentario. En sus peticiones de las décadas de 1580 y 1590, los señores Chachapoyas, primero don Baltasar Solsol y luego don Domingo Jaulis, pidieron títulos a las tierras de Chiara siempre «por si y los yndios subjetos», esto es, en nombre del grupo al que gobernaban, como recursos comunales (sapsi) y no como tierras a título personal (Zorrilla, 1977: 1v, 19v-20r). En contraste, a pesar de que Martín de Ayala e Inés Coca identificaron a sus ancestros como señores de Santa Catalina de Chupas, nunca reclamaron los terrenos en nombre de algún grupo étnico a ellos sujeto. Si todavía tenían algún tipo de autoridad étnica sobre los indios cavinas a quienes don Juan Tingo había gobernado, ¿por qué entonces los chachapoyas se declararon «amigos y conformes» con los cavinas, a quienes supuestamente les estaban usurpando sus tierras en Chupas (Zorrilla, 1977: f. 25v)? En 1570, como ya se mencionó, don Juan Tingo había reclamado ciertos cocales para su ayllu. Tal parece que dicha práctica, asociada con la autoridad andina tradicional, desapareció, al menos entre sus descendientes, con la muerte del señor Cavina. Beneficiándose del estatus que reinventaron para sus ancestros como caciques del valle y pueblo de Chupas, los herederos de Tingo intentaron acumular tierras previamente comunes según premisas más individualistas, presentándolas como tierras familiares susceptibles de ser heredadas privadamente.

De forma similar, ¿̇a quiénes representaba Felipe Guaman Poma cuando se presentó ante las autoridades como «Casique Prinçipal Governador de los yndios», así, a secas (Prado \& Prado, 1991: ff. 55r-55v)? ¿Por qué no utilizó algunos de los argumentos esgrimidos en la Nueva corónica acerca de que la tierra debía permanecer entre las comunidades indígenas por ser sapsi, cosa común de todos? ¿Las tierras de quién decía administrar Guaman Poma?

23 No es exacto que, tal como afirma Adorno (2000: xxiv-xxvii), el estatus de mitimae fuera un obstáculo para reclamar tierras. El Rey ordenó en 1539 que, siempre que fuera posible, los mitimaes no regresaran a sus lugares de origen y que las autoridades protegieran las tierras que venían explotando de posibles intrusos. Véase AGI, 1539, Lima, 565. Leg. 3: f. 121v. 
Los funcionarios coloniales finalmente rechazaron las pretensiones del cronista como «cacique de Rantavilca» en 1600, pues, entre otras razones, Guaman Poma no parecía tener indios a quienes representar. Las autoridades nunca cuestionaron, sin embargo, la legitimidad étnica de los jefes Chachapoyas ni la de los aliados legales de Guaman Poma, descendientes de los reinventados señores de Chupas. La sentencia afirma que Guaman Poma, mas no los otros litigantes, había sido declarado como «no parte» en la causa, otro aspecto usualmente ignorado de esta historia. $\mathrm{Si}$, tal como afirmaron los chachapoyas, Guaman Poma era un cacique impostor y un falso heredero a las tierras en disputa (además de ser un personaje cuya presencia era tardía en el juicio), quizás cobre mayor sentido el sostener que tanto Tingos cuanto Ayalas lo reclutaran como a una suerte de procurador y representante legal, guiados por su sobresaliente experiencia judicial en asuntos de tierras. Si los Tingos y Ayalas eran efectivamente parientes cercanos del cronista, es preciso entonces concluir que, en los años postreros del siglo XVI, Guaman Poma se vio envuelto, como principal protagonista, en una típica historia en la cual los descendientes de antiguos señores aunaron esfuerzos para apropiarse, esta vez a título individual o familiar, de terrenos y recursos previamente comunes y abiertos al uso de varios grupos étnicos.

Tanto los chachapoyas cuanto los Tingos y Ayalas ejemplifican distintas fases en el proceso de transición desde el sistema prehispánico de uso de la tierra hacia el sistema europeo introducido con la Conquista. No debe olvidarse que la postura y los argumentos legales de los señores Chachapoyas, actuando en nombre de los indios de su comunidad, representaban todavía un estadío previo en el camino hacia la privatización de la tierra y de los intereses nativos, un concepto sobre la tierra, podríamos agregar, menos individualista y más cercano a la tradición andina prehispánica de sapsi, el «punto de vista nativo» que la tradición etnohistórica tanto busca esclarecer. Creo haber demostrado que las interpretaciones previas sobre este episodio, sin duda influidas por la enorme importancia de Guaman Poma y de la Nueva corónica para los estudios andinos, habían asumido que, en lo que respecta a la tierra, el punto de vista del «cronista y príncipe» representaba, como en muchos otros casos, la verdadera voz indígena, o al menos la voz de aquellas comunidades nativas operando aún bajo los principios tradicionales de uso de la tierra y ocupación del espacio en Huamanga. Sin embargo, ni las autoridades locales ni sus rivales legales indígenas pudieron desposeer a Guaman Poma y al bando legal al que representaba de algo que ni ellos ni sus ancestros pudieron haber realmente poseído a título individual o familiar. La historia en cambio, parece haber sido precisamente la opuesta: la apropiación de tierras gracias a la alianza de caciques coloniales e indios ladinos, buenos conocedores del sistema legal español.

Antes que un ataque contra Felipe Guaman Poma, una visión alternativa sobre los acontecimientos que sustentaban la tesis previa de la desposesión colonial no solo devuelve la lógica Post-Conquista a sus actores -incluido el futuro cronista-, sino que provee una interpretación más histórica sobre las batallas legales de Chupas, estimulando futuras discusiones sobre el lugar que en ellas realmente ocuparon Felipe Guaman Poma y su visión colonial del espacio, el territorio y la tierra. Para entender la verdadera lógica detrás de este famoso episodio, así como la naturaleza de los títulos de Guaman Poma y de muchos otros andinos a las tierras «ancestrales», debemos partir del hecho, a veces difícil de imaginar, que las nociones occidentales de posesión exclusiva de la tierra no son aplicables a la Huamanga prehispánica. En términos estrictos, todos los títulos indígenas, sean estos «prehispánicos» o coloniales, son títulos inventados, artefactos híbridos por definición, y es precisamente esta idea la que debería guiar nuestros esfuerzos al analizar las miles de disputas legales por tierras que inundan los archivos coloniales y republicanos. 


\section{Referencias citadas}

\section{Fuentes primarias}

\section{Archivo General de Indias (AGI)}

1539

1548-1595

1570-1600

1596-1601

$1713-1717$
Lima, 565. Leg. 3: f. 121v

Patronato, 95B, r. 8: ff. 20-23

Lima, 136

Lima, 199, 18

Escribanía de Cámara, 519B: f. 100v-108r

\section{Fuentes secundarias}

ABERCROMBIE, T., 1998 - Pathways of Memory and Power: Ethnography and History among an Andean People, 603 p.; Madison: University of Wisconsin Press.

ADORNO, R., 1978 - Felipe Guaman Poma de Ayala: An Andean View of the Peruvian Viceroyalty, 1565-1615. Journal de la Société des Américanistes, 55: 121-143; París.

ADORNO, R., 1979 - Icon and Idea: A Symbolic Reading of Pictures in a Peruvian Indian Chronicle. The Indian Historian, 12 (3): 27-50; San Francisco.

ADORNO, R., 1982 - The Language of History in Guaman Poma's Nueva corónica y buen gobierno. In: From Oral to Written Expression: Native Andean Chronicles of the Early Colonial Period (R. Adorno, ed.): 109-173; Syracuse: Syracuse University.

ADORNO, R., 1987 - Waman Puma: el autor y su obra. In: Felipe Guaman Poma de Ayala. Nueva crónica y buen gobierno (J. V. Murra, R. Adorno \& J. L. Urioste, eds.): xviixlvii; Madrid: Historia-16.

ADORNO, R., 1991 - La visión del visitador y el indio ladino. In: Cultures et Sociétés, Andes et Méso-Amérique. Mélanges en Hommage à Pierre Duviols, (R. Thiercelin, ed.): 3550; Aix-en-Provence: Université de Provence.

ADORNO, R., 1992 - Colonial Reform of Utopia? Guaman Poma's Empire of the Four Parts of the World. In: Amerindian Images and the Legacy of Columbus (R. Jara \& N. Spadaccini, eds.): 346-374; Minneapolis: University of Minnesota.

ADORNO, R., 1993 - The Genesis of Felipe Guaman Poma de Ayala's Nueva corónica y buen gobierno. Colonial Latin American Review, 2 (1-2): 53-91; Nueva York.

ADORNO, R., 2000 - Guaman Poma: Writing and Resistance in Colonial Peru, 194 p.; Austin: University of Texas Press.

ADORNO, R., 2001 - Guaman Poma and His Illustrated Chronicle from Colonial Peru: From a Century of Scholarship to a New Era of Reading, 88 p.; Copenhague: Museum Tusculanum Press, University of Copenhage y The Royal Library of Denmark.

ADORNO, R. \& BOSERUP, I., 2005 - Guaman Poma and the Manuscripts of Fray Martín de Murúa. Prolegomena to a Critical Edition of the Historia del Perú. Fund og Forskning, 44: 105-258.

ARCHIVO REGIONAL DEL CUZCO, 1957 - Reparto de tierras en 1595. Revista del Archivo Histórico del CuzCo, 8: 389-432. 
ARRIAGA, P. J., 1999 [1621] - La extirpación de la idolatría en el Pirú, 200 p.; Cuzco: Centro de Estudios Regionales Andinos «Bartolomé de Las Casas».

BANDERA, D. de la, 1965 [1557] - Relación general de la disposición y calidad de la provincia de Guamanga, Ilamada San Joan de la Frontera, y de la vivienda y costumbres de los naturales della. In: Relaciones Geográficas de Indias. Perú. 3 vols. (M. Jiménez de la Espada, ed.), 1: 178-180; Madrid: Atlas.

BEYERSDORFF, M., 2002 - Caminos rituales y cartografía indígena: la vigencia de la relación de las guacas del Cuzco de Bernabé Cobo en su época. In: Incas e indios cristianos: elites indígenas e identidades cristianas en los Andes coloniales (J.-J. Decoster, ed.): 39-60; Cuzco: Centro de Estudios Regionales Andinos Bartolomé de Las Casas, Asociacion Kuraka, Instituto Francés de Estudios Andinos.

BEYERSDORFF, M., 2005 - Writing Without Words/Words Without Writing: The Culture of the Khipu. Latin American Research Review, 40 (3): 294-311; Austin.

CERRÓN-PALOMINO, R., 1992 - Hurin: un espejismo léxico opuesto a hanan. In: El hombre y los Andes: homenaje a Franklin Pease G.Y. (J. Flores Espinoza \& R. Varón Gabai, eds.): 219-235; Lima: Instituto Francés de Estudios Andinos, Pontificia Universidad Católica del Perú, Banco de Crédito del Perú, Fundación Telefónica.

CHANG-RODRÍGUEZ, R., 1995 - Las ciudades de Primer nueva corónica y los mapas de las Relaciones geográficas de Indias: un posible vínculo. Revista de Crítica Literaria Latinoamericana, 23 (41): 95-119; New Hampshire.

CHANG-RODRÍGUEZ, R., 2005 - La palabra y la pluma en Primer nueva corónica y buen gobierno, 2005 p.; Lima: Pontificia Universidad Católica del Perú.

CRESPO, J. C., 1974 [1558] - La relación de Chincha (1558). Historia y Cultura, 8: 91-104; Lima.

ESPINOZA SORIANO, W., 1978 - Los chachapoyas y cañares de Chiara (Huamanga), aliados de España. In: Historia: problema y promesa. Homenaje a Jorge Basadre, 2 vols., (F. Miró Quesada, F. Pease \& D. Sobrevilla, eds.), 1: 231-253; Lima: Pontificia Universidad Católica del Perú.

GONZÁLEZ HOLGUíN, D., 1952 - Vocabulario de la lengua general de todo el Perú, llamada lengua qquichua o del inca, 697 p.; Lima: Santa María.

GRUZINSKI, S., 1993 - The Conquest of Mexico: The Incorporation of Indian Societies into the Western World, 16th-18th Centuries, 336 p.; Cambridge: Polity Press.

GUAMAN POMA DE AYALA, F., 1992 - El primer nueva corónica y buen gobierno, 3ra. ed. (J. Murra, R. Adorno \& J. Urioste, eds.), 1173 p.; México D.F.: Siglo XXI.

GUEVARA GIL, A., 1993 - Propiedad agraria y derecho colonial: los documentos de la hacienda Santotis, Cuzco (1543-1822), 572 p.; Lima: Pontificia Universidad Católica del Perú.

GUILLÉN, E., 1969 - El cronista don Felipe Guaman Poma y los manuscritos hallados en el pueblo de Chiara. Amaru, 10: 89-92; Lima.

HUERTAS, L., 1981 - Poblaciones indígenas en Huamanga colonial. In: Etnohistoria y antropología andina (A. Castelli, M. Koth de Paredes \& M. Mould, eds.): 131-144; Lima: Pontificia Universidad Católica del Perú

HUERTAS, L., 1998 - Conformación del espacio social en Huamanga, siglos XV y XVI. In: Historia, religión y ritual de los pueblos ayacuchanos (L. Millones, H. Tomoeda \& T. Fujii, eds.): 7-28; Osaka: National Museum of Ethnology.

HUSSON, J. P., 1995 - En busca de las fuentes indígenas de Waman Puma de Ayala. Las raíces incas y yaruwillka del cronista indio: ¿invención o realidad? Histórica, 19 (1): 29-71; Lima. 
ISBELL, B. J., 1985 - To Defend Ourselves: Ecology and Ritual in an Andean Village, 289 p.; Illinois: Waveland Press.

KUMAI, S., 2002 - Las fronteras y los límites del Tahuantinsuyo: «el Tahuantinsuyo de cada rey Inca» que debe reconfirmarse. In: El hombre y los Andes: homenaje a Franklin Pease G.Y. (J. Flores Espinoza \& R. Varón Gabai, eds.): 617-637; Lima: Instituto Francés de Estudios Andinos, Pontificia Universidad Católica del Perú, Banco de Crédito del Perú, Fundación Telefónica.

LEIBSHON, D., 1994 - Primers for Memory: Cartographic Histories and Nahua Identity. In: Writing without Words: Alternative Literacies in Mesoamerica and the Andes (E. Hill Boone \& W. Mignolo, eds.): 161-187; Durham: Duke University Press.

LEIBSHON, D., 1995 - Colony and Cartography: Shifting Signs on Indigenous Maps of New Spain. In: Reframing the Renaissance: Visual Culture in Europe and Latin America, 1450-1650 (C. J. Farago, ed.): 265-281; New Haven: Yale University Press.

LEVILLIER, R., 1940 - Don Francisco de Toledo, supremo organizador del Perú. Su vida, su obra (1515-1582). Tomo II: Sus informaciones sobre los Incas (1570-1572), 516 p.; Buenos Aires: Porter.

LOCKHART, J., 1983 - Views of Corporate Self and History in Some Valley of Mexico Towns: Late Seventeenth and Eighteenth Centuries. In: The Inca and Aztec States, 1400-1800: Anthropology and History (G. Collier, R. Rosaldo \& J. Wirth, eds.): 367393; New York: Academic Press.

LOCKHART, J., 1985 - Some Nahua Concepts in Postconquest Guise. History of European Ideas, 6 (4): 465-482; New York.

LÓPEZ-BARALT, M., 1979 - La persistencia de las estructuras simbólicas andinas en los dibujos de Guaman Poma de Ayala. Journal of Latin American Lore, 5 (1): 83-116; Los Ángeles.

LÓPEZ-BARALT, M., 1992 - From Looking to Seeing: The Image as Text and the Author as Artist. In: Guaman Poma De Ayala: The Colonial Art of an Andean Author (R. Adorno et al., eds.): 14-31; Nueva York: The Americas Society.

MACERA, P., 1991 - Introducción. In: Phelipe Guaman Poma de Ayala: Y no ay remedio (E. Prado Tello \& A. Prado, eds.): 23-80; Lima: Centro de Investigación y Promoción Amazónica.

MEDELIUS, M. \& PUENTE LUNA, J. C. de la, 2004 - Curacas, bienes y quipus en un documento toledano (Jauja, 1570). Histórica, 28 (2): 35-82; Lima.

MONZÓN, L., 1965a [1586] - Descripción de la tierra del repartimiento de San Francisco de Atunrucana y Laramati, encomendado en don Pedro de Córdova, jurisdicción de la ciudad de Guamanga. In: Relaciones geográficas de Indias. Perú. 3 vols. (M. Jiménez de la Espada, ed.), 1: 228-236; Madrid: Atlas.

MONZÓN, L., 1965b [1586] - Descripción de la tierra del repartimiento de los rucanas antamarcas de la corona real, jurisdicción de la ciudad de Guamanga. In: Relaciones geográficas de Indias. Perú. 3 vols. (M. Jiménez de la Espada, ed.), 1: 237-248; Madrid: Atlas.

MOROTE BEST, E., 1975 - Huamanga entre 1539 y 1547 (examen del primer libro del Cabildo), 91 p.; Lima: Jurídica.

MURRA, J. V., 1975 - El control vertical de un máximo de pisos ecológicos en la economía de las sociedades andinas. In: Formaciones económicas y políticas del mundo andino: 59-115; Lima: Instituto de Estudios Peruanos.

MURRA, J. V., 1980a - The Economic Organization of the Inka State, 208 p.; Connecticut: Jai Press. 
MURRA, J. V., 1980b - Derechos a las tierras en el Tawantinsuyu. Revista de la Universidad Complutense, 28 (117): 273-287; Madrid.

MURRA, J. V., 1987 - Una visión indígena del mundo andino. In: Felipe Guaman Poma de Ayala. Nueva crónica y buen gobierno (J. V. Murra, R. Adorno \& J. L. Urioste, eds.): xlix-Ixiii; Madrid: Historia 16.

MURRA, J. V., 1992a - Waman Puma, etnógrafo del mundo andino. In: El primer nueva corónica y buen gobierno, 3ra. ed. (J. Murra, R. Adorno \& J. Urioste, eds.): xiii-xix.

MURRA, J. V., 1992b - Guaman Poma's Sources. In: Guaman Poma De Ayala: The Colonial Art of an Andean Author (R. Adorno et al., eds.): 60-66; Nueva York: The Americas Society.

NOEJOVICH, H., 1996 - Los albores de la economía americana, 582 p.; Lima: Pontificia Universidad Católica del Perú.

OSSIO, J., 1970 - The Idea of History in Felipe Guaman Poma de Ayala, 312 p.; Oxford University. Tesis (B. Lit.).

OSSIO, J., 1973 - Guaman Poma: Nueva corónica o carta al rey. Un intento de aproximación a las categorías del pensamiento del mundo andino. In: Ideología mesiánica del mundo andino (J. Ossio, ed.): 153-213; Lima: I. Prado Pastor.

PÄRSSINEN, M., 1992 - Tawantinsuyu: The Inca State and Its Political Organization, 462 p.; Helsinki: The Finnish Historical Society.

PEASE, F., 1986 - La noción de propiedad entre los Incas: una aproximación. In: Etnografía e historia del mundo andino (S. Masuda, ed.): 3-33; Tokio: University of Tokyo.

PEASE, F., 1992 - Curacas, reciprocidad y riqueza, 208 p., Lima: Pontificia Universidad Católica del Perú.

PEREYRA, N., 1997 - Un documento sobre Guaman Poma de Ayala existente en el Archivo Departamental de Ayacucho. Histórica, 21 (2): 261-270; Lima.

POLO DE ONDEGARDO, J. 1906 - Los errores y supersticiones de los indios sacados del tratado y averiguación que hizo el licenciado Polo de Ondegardo. Revista Histórica, 1: 207-231; Lima.

PORRAS, R., 1948 - El cronista indio Felipe Huamán Poma de Ayala, 110 p.; Lima: Lumen.

POWERS, K., 1995 - Andean Journeys: Migration, Ethnogenesis, and the State in Colonial Quito, 232 p.; Albuquerque: University of New Mexico Press.

PRADO TElLO, E. \& PRADO, A. (eds.), 1991 - Phelipe Guaman Poma de Ayala: Y no ay remedio, 410 p.; Lima: Centro de Investigación y Promoción Amazónica.

PUENTE LUNA, J. C. de la \& SOLIER OCHOA, V., 2007 - La sombra del intérprete: Felipe Guaman Poma de Ayala y la primera composición general de tierras en el virreinato del Perú. Manuscrito.

RADCLIFFE, S., 1990 - Marking the Boundaries between the Community, the State and History in the Andes. Journal of Latin American Studies, 22: 575-594; Nueva York.

RAMÍREZ, S., 1996 - The World Upside Down: Cross-Cultural Contact and Conflict in Sixteenth-Century Peru, 234 p.; Stanford: Stanford University Press.

RAMÍREZ, S., 2005 - To Feed and Be Fed: The Cosmological Bases of Authority and Identity in the Andes, 358 p; Stanford: Stanford Univ. Press.

RIBERA, P. \& CHAVES, A., 1965 [1585] - Relación de la ciudad de Guamanga y sus términos. In: Relaciones geográficas de Indias. Perú. 3 vols. (M. Jiménez de la Espada, ed.), 1: 181-201; Madrid: Atlas.

RIVERA SERNA, R. (ed.), 1966 - Libro del cabildo de la ciudad de San Juan de la Frontera de Huamanga (1539-1547), 207 p.; Lima: Casa de la Cultura del Perú. 
ROMERO, C., 1919 [1613] - Idolatrías de los indios huachos y yauyos. Histórica, 6: 180197; Lima.

ROSTWOROWSKI, M., 1988 - Conflicts over Coca Fields in XVIth-Century Peru, 314 p.; Ann Arbor, Lima: University of Michigan Press, Instituto de Estudios Peruanos.

ROWE, J., 1957 - The Incas under Spanish Colonial Institutions. Hispanic American Historical Review, 37: 155-199; Durham.

ROWE, J., 1958 - The Age-Grades of the Inca Census. In: Miscellanea Paul Rivet octogenario didacta, 2 vols. (P. Martínez del Río \& P. Bosch-Gimpera, eds.), 2: 499-522; México, D. F.: Universidad Nacional Autónoma de México.

ROWE, J., 1982 - Inca Policies and Institutions Relating to the Cultural Unification of the Empire. In: The Inca and Aztec States, 1400-1800: Anthropology and History (G. Collier, R. Rosaldo \& J. Wirth, eds.): 93-118; New York: Academic Press.

SPALDING, K., 1984 - Huarochirí: An Andean Society under Inca and Spanish Rule, 364 p.; Stanford: Stanford University Press.

STERN, S., 1978 - Algunas consideraciones sobre la personalidad histórica de don Felipe Guaman Poma de Ayala. Histórica, 2 (2): 225-228; Lima.

STERN, S., 1993 - Peru's Indian Peoples and the Challenge of Spanish Conquest, 295 p.; Madison: The University of Wisconsin Press.

TAYLOR, G. (ed.), 1999 [c. 1608] - Ritos y tradiciones de Huarochirí, 502 p.; Lima: Instituto Francés de Estudios Andinos, Banco Central de Reserva del Perú.

THURNER, M., 1997 - From Two Republics to One Divided: Contradictions of Postcolonial Nationmaking in Andean Peru, 203 p.; Durham: Duke University Press.

TORRES SALDAMANDO, E., 1888 - Libro primero de cabildos de Lima. Segunda parte. Apéndices, 3 vols.; París: Paul Dupont.

VACA DE CASTRO, C., 1908 - Ordenanzas de tambos. Revista Histórica, 3: 427-492; Lima.

VARALLANOS, J., 1979 - Guaman Poma de Ayala: cronista precursor y libertario, 242 p.; Lima: G. Herrera.

WACHTEL, N., 1973 - Pensamiento salvaje y aculturación: el espacio y el tiempo en Felipe Guaman Poma de Ayala y el Inca Garcilaso de la Vega. In: Sociedad e ideología: ensayos de historia y antropología andinas: 165-228; Lima: Instituto de Estudios Peruanos.

WACHTEL, N., 1977 - The Vision of the Vanquished: The Spanish Conquest of Peru through Indian Eyes, 1530-1570, 328 p.; Nueva York: Barnes \& Noble.

WACHTEL, N., 1982 - The Mitimas of the Cochabamba Valley: The Colonization Policy of Huayna Capac. In: The Inca and Aztec States, 1400-1800: Anthropology and History (G. Collier, R. Rosaldo \& J. Wirth, eds.): 367-393; New York: Academic Press.

ZORRILLA, J. C., 1977 - La posesión de Chiara por los indios Chachapoyas. Wari, 1: 4964; Ayacucho.

ZUIDEMA, T., 1967 - Algunos problemas etnohistóricos del departamento de Ayacucho. Wamani, 1: 68-75; Ayacucho. 